\title{
Determination Method of Sequence Distribution for Bi-component Copolymer System in Which One Monomer Unit Only Has Stereoregularity and Its Application for Poly(acrylonitrile-co-vinylidene chloride)
}

\author{
Kunio Hisatani, ${ }^{*}$ Kunihiko OKaJIma, ${ }^{*}$ and Kenji Kamide** \\ * Fundamental Research Laboratory of Natural and Synthetic Polymers, \\ Asahi Chemical Industry Co., Ltd., \\ 11-7 Hacchonawate Takatsuki, Osaka 569, Japan \\ ** Faculty of Education, Kumamoto University, \\ 2-40-1 Kurokami, Kumamoto 860, Japan
}

(Received January 17, 1995)

\begin{abstract}
An attempt was made to extend the method for explaining monomer unit sequence distribution of a bi-component copolymer system proposed already by Kamide and Hisatani, in which both monomer units have possibility of yielding stereoregular homopolymers, to the system in which only one monomer is capable to give stereoregular homopolymer. The method includes a concept of correlation and non-correlation between sequence distributions of monomer unit and its cotacticity, and all of expressions of pentad sequences are described. Simultaneously, the sort of four kinds of $n$-length bi-component copolymer sequence has been enumerated up employing difference equation method, in which copolymer system only one monomer unit has stereoregularity. The method established in this paper was applied to poly(acrylonitrile-co-vinylidene chloride) sample as a model copolymer, of which ${ }^{13} \mathrm{C}$ NMR peak assignment was already attained based on pentad sequence distribution [H. Yamazaki, K. Okajima, and K. Kamide, Polym. J., 20, 1143 (1988)].
\end{abstract}

KEY WORDS Copolymer Sequence Distribution / Cotacticity / ${ }^{13} \mathrm{C}$ NMR Spectrometer / Bernoulli Statistics / Markov Statistics / Pentad Sequence / Poly(acrylonitrile-co-vinylidene chloride) /

For a long time, many scientists have studied on analytical theory of sequence distribution of homopolymers and copolymers. At about such early age as 1950s, Frisch et al., ${ }^{1}$ Coleman, ${ }^{2}$ Miller and Nielsen, ${ }^{3}$ Fordham, ${ }^{4}$ Price, ${ }^{5}$ and Miyake and Chujo ${ }^{6}$ tried to analyse meso and racemo sequence or $\mathrm{D}$ - and $\mathrm{L}$ - style sequence of homopolymer and monomer unit sequence of copolymer, and Frisch et al. ${ }^{7,8}$ analysed meso and racemo sequence distribution of homopolymers employing the newest nuclear magnetic resonance (NMR) equipment at that days perhaps about $40 \mathrm{MHz}$, but they could hardly achieve satisfactory sequential analysis of real polymers because of elemental lack of experimental data of sequence distribution.

Since Bovey proposed ${ }^{9}$ at 1962 a concept "monomer unit sequence with its cotacticity" in a bi-component copolymer system in which each of both monomer units has a possibility of yielding stereoregular homopolymer, many studies on sequence distributions have been carried out in this field. In that paper, Bovey also proposed a statistical model which first introduced cotacticity parameter $\sigma$, and this model has long been employed to analyze copolymer sequence distribution by many scientists. ${ }^{10-12}$ But all of these studies until 1980s have never handled analytically and 
systematically with triad or higher sequence distributions of monomer unit combined with its stereoregularity.

Recently, remarkable progress of NMR technology has supplied a powerful basis for such analytical studies. Kapur and Brar have assigned all ${ }^{13} \mathrm{C}$ peaks on the basis of all possible 20 triads of poly(acrylonitrile-comethyl methacrylate) ${ }^{13}$ and poly(acrylonitrileco-ethyl methacrylate) $)^{14}$ observed by 100 $\mathrm{MHz}-{ }^{1} \mathrm{H}\left\{{ }^{13} \mathrm{C}\right\}$ NMR. Yamazaki et al. ${ }^{15}$ have given full assignments of 36 pentad peaks of nitrile and methine carbons of poly(acrylonitrile-co-vinylidene chloride) using $200 \mathrm{MHz}$ ${ }^{1} \mathrm{H}\left\{{ }^{13} \mathrm{C}\right\}$ NMR.

The analytical method for monomer unit sequence distribution with coexistence of stereoregularity, however, has not been developed satisfactorily after Bovey's $\sigma$-parameter model in spite of the subsequent remarkable progress of NMR measurement technology and intelligent computer machines.

Very recently, Kamide and Hisatani have proposed a method for determination of the sequence distribution of bi-component copolymers, of which two monomers are both capable of producing stereoregular homopolymers, ${ }^{16}$ applying strictly Markov statistics for the stereoregularity of sequence employing cotacticity, i.e., comeso and coracemo corresponding to meso and racemo, respectively, in homopolymer system, with introduction of a concept of correlation or non-correlation between sequence distributions of monomer unit and its cotacticity. The method has made possible to express copolymer sequence distribution incorporating stereoregularity more precisely than Bovey's $\sigma$-parameter model, and to give more detail information of polymerization mechanism by examining the reaction probability parameters obtained from the most suitable statistics.

In the present article, the method proposed by Kamide and Hisatani ${ }^{16}$ is modified successfully to analyze another bi-component copolymer system in which only one monomer unit has stereoregularity with the enumeration of sorts of copolymer sequence in that system. The method was applied to poly(acrylonitrile (AN)-co-vinylidene chloride $\left.\left(\mathrm{VdCl}_{2}\right)\right)$ sample, of which full assignments of ${ }^{13} \mathrm{C}$ NMR peaks were already made by Yamazaki et al. ${ }^{4}$

\section{THEORETICAL BACKGROUND}

\section{Enumeration of Sorts of Bi-component Copoly-} mer Sequence Consisted of n-Sequential Monomer Units in Which Only One Monomer Unit Has Chirality

Klesper and Sielaff enumerated sorts of three types of bi-component copolymer sequence consisted of $n$-sequential monomer units with or without cotacticity. ${ }^{17}$ In the present article, more systematic enumerations were carried out using difference equation method for bicomponent copolymer sequence in which only one monomer unit has chirality.

Consider first a sequence system consisted of two elements ' $a$ ' and ' $b$ '. That means the system has basic two-element set defined by $C=\{\mathrm{a}, \mathrm{b}\}$. In this sequence system, the case was considered where a diad was constituted of ' $a$ ' elements only, i.e., ('aa'), solely corresponded to an element of other twoelement set, $S=\{\mathrm{s}, \mathrm{t}\}$. This is a general expression for a bi-component copolymer sequence in which one monomer unit only has a possibility of yielding stereoregular homopolymer. In other word, $\mathrm{C}$ and $\mathrm{S}$ are also general expressions for a set of bi-component copolymer units and that of meso $(m)$ and racemo $(r)$, respectively. This means a copolymer sequence system consisted from the complex diad set $X=\left\{\mathrm{A}^{m} \mathrm{~A}, \mathrm{~A}^{r} \mathrm{~A}, \mathrm{AB}, \mathrm{BB}\right\}$, where only $\mathrm{B}$ monomer is not capable to form stereoregular homopolymer. Hereafter, the sequence introduced here is referred to as 'diad-monad sequence' because that diad of set $\{\mathrm{A}, \mathrm{B}\}$ and monad of set $\{m, r\}$ are combined, and monomer unit $\mathrm{A}$ and $\mathrm{B}$ are referred to as $A$ and $B$ unit, respectively.

If a sequence with $i+2$ monomer units in 
which two A units locate at both ends with $i$ sequences of $\mathrm{B}$ units inside and either $\mathrm{A}$ unit is influenced by remote effect caused by the other A unit in NMR, this case should be separately taken into account. Such sequence as ' $\mathrm{A}+i$ sequences of $\mathrm{B}+\mathrm{A}$ ' is referred to as " $i$-remote partial diad-monad sequence".

From now on, general expressions are employed in order to enumerate the sorts of these sequences.

Partial Diad-Monad Directive Sequence. Directive sequences are expressed here with an arrow mark on the element symbols. For examples, two monads are naturally expressed as $\vec{a}$, and $\vec{b}$, and $\overrightarrow{a^{s} a}, \overrightarrow{a^{t} a}, \overrightarrow{a b}, \overrightarrow{b a}$, and $\overrightarrow{b b}$ represent all of five diads. The number of the whole sequences with $n$ monomers (hereafter, referred to like as $n$-length) in which left and right ends are $l$-length sequence $x_{l}$ and $m$-length sequence $y_{m}$, respectively, is defined as ${ }_{x_{l}} N_{y_{m}}(n)$ $(n>l+m)$. If both of $x_{1}$ and $y_{m}$ are monad sequences, ${ }_{\mathrm{a}} N_{\mathrm{b}}(n)$ is , for example, number of sequences, ' $\mathrm{a}+($ arbitrary sequence of $n-2$ monomer units) $+b$ '. The difference equations with matrix and vector form are deducted as follows:

$\left[\begin{array}{c}{ }_{\mathrm{a}} N_{\mathrm{a}}(n) \\ { }_{\mathrm{a}} N_{\mathrm{b}}(n) \\ { }_{\mathrm{b}} N_{\mathrm{a}}(n) \\ { }_{\mathrm{b}} N_{\mathrm{b}}(n)\end{array}\right]=\left[\begin{array}{llll}4 & 2 & 2 & 1 \\ 2 & 1 & 1 & 1 \\ 2 & 1 & 2 & 1 \\ 1 & 1 & 1 & 1\end{array}\right]\left[\begin{array}{c}{ }_{\mathrm{a}} N_{\mathrm{a}}(n-2) \\ { }_{\mathrm{a}} N_{\mathrm{b}}(n-2) \\ { }_{\mathrm{b}} N_{\mathrm{a}}(n-2) \\ { }_{\mathrm{b}} N_{\mathrm{b}}(n-2)\end{array}\right]$

Now, we can calculate the number of $n$ -

Table I. Number of $n$-length sequence for partial diad-monad directive sequence

\begin{tabular}{cccccc}
\hline$n$ & ${ }_{\mathrm{a}} N_{\mathrm{a}}(n)$ & ${ }_{\mathrm{a}} N_{\mathrm{b}}(n)$ & ${ }_{\mathrm{b}} N_{\mathrm{a}}(n)$ & ${ }_{\mathrm{b}} N_{\mathrm{b}}(n)$ & Total number \\
\hline 1 & $(1)^{\mathrm{a}}$ & 0 & 0 & $(1)^{\mathrm{b}}$ & 2 \\
2 & 2 & 1 & 1 & 1 & 5 \\
3 & 5 & 3 & 3 & 2 & 13 \\
4 & 13 & 8 & 8 & 5 & 34 \\
5 & 34 & 21 & 21 & 13 & 89 \\
6 & 89 & 55 & 55 & 34 & 234 \\
\hline
\end{tabular}

${ }^{a} \vec{a}^{b} \vec{b}$. length sequence for ${ }_{\mathrm{a}} N_{\mathrm{a}}(n),{ }_{\mathrm{a}} N_{\mathrm{b}}(n),{ }_{\mathrm{b}} N_{\mathrm{a}}(n)$, and ${ }_{\mathrm{b}} N_{\mathrm{b}}(n)$ by solving the difference equations [eq (1a) - (1d)] and estimate total number of $n$ length sequence counted from ${ }_{\mathrm{a}} N_{\mathrm{a}}(n)+{ }_{\mathrm{a}} N_{\mathrm{b}}(n)+$ ${ }_{\mathrm{b}} N_{\mathrm{a}}(n)+{ }_{\mathrm{b}} N_{\mathrm{b}}(n)$. The detail procedure to solve the difference equations is given in APPENDIX A(1). The results for $n=1-6$ are collected in Table I.

Partial Diad-Monad Non-Directive Sequence. When the sequences are not influenced by the sequential direction, we express the monads as $\bar{a}$ and $\bar{b}$, and the diads as $\overline{a^{s} a}, \overline{a^{t} a}$, $\overline{\mathrm{ab}}$, and $\overline{\mathrm{bb}}$. If the number of symmetric and asymmetric sequences in the whole number corresponding to ${ }_{x_{l}} N_{y_{m}}(n)$ are referred to as ${ }_{x_{l}} g_{x_{l}}(n)$ and ${ }_{x_{l}} h_{y_{m}}(n)$, respectively, difference equations are written as

$\left[\begin{array}{c}{ }_{\mathrm{a}} g_{\mathrm{a}}(n) \\ { }_{\mathrm{b}} g_{\mathrm{b}}(n) \\ { }_{\mathrm{a}} h_{\mathrm{a}}(n) \\ { }_{\mathrm{a}} h_{\mathrm{b}}(n) \\ { }_{\mathrm{b}} h_{\mathrm{b}}(n)\end{array}\right]=\left[\begin{array}{lllll}2 & 1 & 0 & 0 & 0 \\ 1 & 1 & 0 & 0 & 0 \\ 1 & 0 & 4 & 2 & 1 \\ 2 & 1 & 4 & 3 & 1 \\ 0 & 0 & 1 & 1 & 1\end{array}\right]\left[\begin{array}{c}{ }_{\mathrm{a}} g_{\mathrm{a}}(n-2) \\ { }_{\mathrm{b}} g_{\mathrm{b}}(n-2) \\ { }_{\mathrm{a}} h_{\mathrm{a}}(n-2) \\ { }_{\mathrm{a}} h_{\mathrm{b}}(n-2) \\ { }_{\mathrm{b}} h_{\mathrm{b}}(n-2)\end{array}\right]$

The number of five types of $n$-length sequence, ${ }_{\mathrm{a}} g_{\mathrm{a}}(n),{ }_{\mathrm{b}} g_{\mathrm{b}}(n),{ }_{\mathrm{a}} h_{\mathrm{a}}(n),{ }_{\mathrm{a}} h_{\mathrm{b}}(n)$ and ${ }_{\mathrm{b}} h_{\mathrm{b}}(n)$, can be calculated by the method shown in APPENDIX $\mathrm{A}(2)$, and total number of $n$-length sequence can be calculated from an expression, ${ }_{\mathrm{a}} g_{\mathrm{a}}(n)+$ ${ }_{\mathrm{b}} g_{\mathrm{b}}(n)+{ }_{\mathrm{a}} h_{\mathrm{a}}(n)+{ }_{\mathrm{a}} h_{\mathrm{b}}(n)+{ }_{\mathrm{b}} h_{\mathrm{b}}(n)$.

Table II collects the number of $n$-length sequence in this case.

i-Remote Partial Diad-Monad Directive Se-

Table II. Number of $n$-length sequence for partial diad-monad non-directive sequence

\begin{tabular}{ccccccc}
\hline$n$ & ${ }_{\mathrm{a}} g_{\mathrm{a}}(n)$ & ${ }_{\mathrm{b}} g_{\mathrm{b}}(n)$ & ${ }_{\mathrm{a}} h_{\mathrm{a}}(n)$ & ${ }_{\mathrm{a}} h_{\mathrm{b}}(n)$ & ${ }_{\mathrm{b}} h_{\mathrm{b}}(n)$ & Total \\
\hline 1 & $(1)^{\mathbf{a}}$ & $(1)^{\mathrm{b}}$ & 0 & 0 & 0 & 2 \\
2 & 2 & 1 & 0 & 1 & 0 & 4 \\
3 & 3 & 2 & 1 & 3 & 0 & 9 \\
4 & 5 & 3 & 4 & 8 & 1 & 21 \\
5 & 8 & 5 & 13 & 21 & 4 & 51 \\
\hline
\end{tabular}

${ }^{\mathrm{a}} \overline{\mathrm{a}}^{\mathrm{b}} \overline{\mathrm{b}}$. 
quence. In the $i$-remote partial diad-monad directive sequence systems including $a b^{i} a\left(b^{i}\right.$ means $i$-length sequence consisted of element b only), here a system with $i=1$ is considered. For convenience' sake, if single and double prime mean $n$ - and ( $n$-2)-length sequence, respectively, the difference equations in this system are expressed with single and double prime of parameters, ${ }_{\mathrm{a}} N_{\mathrm{a}}(n),{ }_{\mathrm{a}} N_{\mathrm{ab}}(n),{ }_{\mathrm{a}} N_{\mathrm{bb}}(n)$, ${ }_{\mathrm{ba}} N_{\mathrm{a}}(n),{ }_{\mathrm{bb}} N_{\mathrm{a}}(n),{ }_{\mathrm{ba}} N_{\mathrm{ab}}(n),{ }_{\mathrm{ba}} N_{\mathrm{bb}}(n),{ }_{\mathrm{bb}} N_{\mathrm{ab}}(n)$, and ${ }_{\mathrm{bb}} N_{\mathrm{bb}}(n)$, as follows:

$$
\left[\begin{array}{c}
{ }_{\mathrm{a}} N_{\mathrm{a}}^{\prime \prime} \\
{ }_{\mathrm{a}} N_{\mathrm{ab}}^{\prime \prime} \\
{ }_{\mathrm{a}} N_{\mathrm{bb}}^{\prime \prime} \\
{ }_{\mathrm{ba}} N_{\mathrm{a}}^{\prime \prime} \\
{ }_{\mathrm{bb}} N_{\mathrm{a}}^{\prime \prime} \\
{ }_{\mathrm{ba}} N_{\mathrm{ab}}^{\prime \prime} \\
{ }_{\mathrm{ba}} N_{\mathrm{bb}}^{\prime \prime} \\
{ }_{\mathrm{bb}} N_{\mathrm{ab}}^{\prime \prime} \\
{ }_{\mathrm{bb}} N_{\mathrm{bb}}^{\prime \prime}
\end{array}\right]=\left[\begin{array}{lllllllll}
4 & 4 & 2 & 4 & 2 & 4 & 2 & 2 & 1 \\
2 & 0 & 0 & 2 & 1 & 0 & 0 & 0 & 0 \\
0 & 2 & 2 & 0 & 0 & 2 & 2 & 1 & 1 \\
2 & 2 & 1 & 0 & 0 & 0 & 0 & 0 & 0 \\
0 & 0 & 0 & 2 & 2 & 2 & 1 & 2 & 1 \\
1 & 0 & 0 & 0 & 0 & 0 & 0 & 0 & 0 \\
0 & 1 & 1 & 0 & 0 & 0 & 0 & 0 & 0 \\
0 & 0 & 0 & 1 & 1 & 0 & 0 & 0 & 0 \\
0 & 0 & 0 & 0 & 0 & 1 & 1 & 1 & 1
\end{array}\right]\left[\begin{array}{l}
{ }_{\mathrm{a}} N_{\mathrm{a}}^{\prime} \\
{ }_{\mathrm{a}} N_{\mathrm{ab}}^{\prime} \\
{ }_{\mathrm{a}} N_{\mathrm{bb}}^{\prime} \\
{ }_{\mathrm{ba}} N_{\mathrm{a}}^{\prime} \\
{ }_{\mathrm{bb}} N_{\mathrm{a}}^{\prime} \\
{ }_{\mathrm{ba}} N_{\mathrm{ab}}^{\prime} \\
{ }_{\mathrm{ba}} N_{\mathrm{bb}}^{\prime} \\
{ }_{\mathrm{bb}} N_{\mathrm{ab}}^{\prime} \\
{ }_{\mathrm{bb}} N_{\mathrm{bb}}^{\prime}
\end{array}\right] .
$$

Table III compiles the concrete values of number of $n$-order sequences obtained from summing up all the elements of each order vector using these equations.

1-Remote Partial Diad-Monad Non-Directive Sequence. If single and double prime also mean $n$ - and (n-2)-length sequence, respectively, the difference equations are:

$$
\left[\begin{array}{c}
{ }_{\mathrm{a}} g_{\mathrm{a}}^{\prime \prime} \\
{ }_{\mathrm{ba}} g_{\mathrm{ab}}^{\prime \prime} \\
{ }_{\mathrm{bb}} g_{\mathrm{bb}}^{\prime \prime} \\
{ }_{\mathrm{a}} h_{\mathrm{a}}^{\prime \prime} \\
{ }_{\mathrm{a}} h_{\mathrm{ab}}^{\prime \prime} \\
{ }_{\mathrm{a}} h_{\mathrm{bb}}^{\prime \prime} \\
{ }_{\mathrm{ba}} h_{\mathrm{a}}^{\prime \prime} \\
{ }_{\mathrm{ba}} h_{\mathrm{ab}}^{\prime \prime} \\
{ }_{\mathrm{bb}} h_{\mathrm{bb}}^{\prime \prime}
\end{array}\right]=\left[\begin{array}{lllllllll}
2 & 2 & 1 & 0 & 0 & 0 & 0 & 0 & 0 \\
1 & 0 & 0 & 0 & 0 & 0 & 0 & 0 & 0 \\
0 & 1 & 1 & 0 & 0 & 0 & 0 & 0 & 0 \\
1 & 1 & 0 & 4 & 4 & 2 & 4 & 2 & 1 \\
2 & 0 & 0 & 2 & 2 & 1 & 0 & 0 & 0 \\
0 & 2 & 1 & 0 & 2 & 2 & 4 & 3 & 1 \\
0 & 0 & 0 & 1 & 0 & 0 & 0 & 0 & 0 \\
0 & 0 & 0 & 0 & 1 & 1 & 0 & 0 & 0 \\
0 & 0 & 0 & 0 & 0 & 0 & 1 & 1 & 1
\end{array}\right] \quad\left[\begin{array}{c}
{ }_{\mathrm{a}} g_{\mathrm{a}}^{\prime} \\
{ }_{\mathrm{ba}} g_{\mathrm{ab}}^{\prime} \\
{ }_{\mathrm{bb}} g_{\mathrm{bb}}^{\prime} \\
{ }_{\mathrm{a}}^{\prime} h_{\mathrm{a}}^{\prime} \\
{ }_{\mathrm{a}} h_{\mathrm{ab}}^{\prime} \\
{ }_{\mathrm{a}} h_{\mathrm{bb}}^{\prime} \\
{ }_{\mathrm{ba}} h_{\mathrm{a}}^{\prime} \\
{ }_{\mathrm{ba}} h_{\mathrm{ab}}^{\prime} \\
{ }_{\mathrm{bb}} h_{\mathrm{bb}}^{\prime}
\end{array}\right] .
$$

Table III. Number of $n$-length sequence for 1-remote partial diad-monad directive sequence

\begin{tabular}{rccccccccccc}
\hline$n$ & ${ }_{\mathrm{a}} N_{\mathrm{a}}$ & ${ }_{\mathrm{b}} N_{\mathrm{ab}}$ & ${ }_{\mathrm{a}} N_{\mathrm{bb}}$ & ${ }_{\mathrm{ba}} N_{\mathrm{a}}$ & ${ }_{\mathrm{bb}} N_{\mathrm{a}}$ & ${ }_{\mathrm{ba}} N_{\mathrm{ab}}$ & ${ }_{\mathrm{ba}} N_{\mathrm{bb}}$ & ${ }_{\mathrm{bb}} N_{\mathrm{ab}}$ & ${ }_{\mathrm{bb}} N_{\mathrm{bb}}$ & Total \\
\hline 1 & $(1)^{\mathrm{a}}$ & 0 & 0 & 0 & 0 & 0 & 0 & 0 & $(1)^{\mathrm{b}}$ & 2 \\
2 & 2 & $(1)^{\mathrm{c}}$ & 0 & $(1)^{\mathrm{d}}$ & 0 & 0 & 0 & 0 & $(1)^{\mathrm{e}}$ & 5 \\
3 & 6 & 2 & 1 & 2 & 1 & $(1)^{\mathrm{f}}$ & 0 & 0 & $(1)^{\mathrm{g}}$ & 14 \\
4 & 13 & 6 & 3 & 6 & 3 & 2 & 1 & 1 & 1 & 36 \\
5 & 49 & 17 & 9 & 17 & 9 & 6 & 3 & 3 & 2 & 115 \\
\hline
\end{tabular}

$\mathrm{a}^{\mathrm{a}} \overrightarrow{\mathrm{b}}^{\mathrm{c}} \overrightarrow{\mathrm{ab}}^{\mathrm{d}} \overrightarrow{\mathrm{ba}}^{\mathrm{e}} \overrightarrow{\mathrm{bb}} \mathrm{f} \overrightarrow{\mathrm{bab}} \mathrm{s} \overrightarrow{\mathrm{bbb}}$ 
Table IV. Number of n-length sequence for 1-remote partial diad-monad non-directive sequence

\begin{tabular}{ccccccccccc}
\hline$n$ & ${ }_{\mathrm{a}} g_{\mathbf{a}}$ & ${ }_{\mathrm{ba}} g_{\mathrm{ab}}$ & ${ }_{\mathrm{bb}} g_{\mathrm{bb}}$ & ${ }_{\mathrm{a}} h_{\mathrm{a}}$ & ${ }_{\mathbf{a}} h_{\mathrm{ab}}$ & ${ }_{\mathbf{a}} h_{\mathrm{bb}}$ & ${ }_{\mathrm{ba}} h_{\mathrm{ab}}$ & ${ }_{\mathrm{ba}} h_{\mathrm{ab}}$ & ${ }_{\mathrm{bb}} h_{\mathrm{bb}}$ & Total \\
\hline 1 & $(1)^{\mathrm{a}}$ & 0 & $(1)^{\mathbf{b}}$ & 0 & 0 & 0 & 0 & 0 & 0 & 2 \\
2 & 2 & 0 & $(1)^{\mathrm{c}}$ & 0 & $(1)^{\mathrm{d}}$ & 0 & 0 & 0 & 0 & 4 \\
3 & 4 & $(1)^{\mathrm{e}}$ & $(1)^{\mathrm{f}}$ & 1 & 2 & 1 & 0 & 0 & 0 & 10 \\
4 & 5 & 2 & 1 & 6 & 6 & 2 & 0 & 1 & 0 & 27 \\
5 & 11 & 4 & 2 & 19 & 15 & 9 & 1 & 3 & 0 & 64 \\
\hline
\end{tabular}

${ }^{a} \bar{a}^{b} \bar{b}^{c} \overline{b b} d \overline{a b}{ }^{e} \overline{b a b}{ }^{f} \overline{b b b}$

Enumeration of each order sequence length can be carried out by summing up all the elements of the vector of that order. Table IV collects the concrete values of number from 1 st to 5 th-order sequences.

\section{Statistical Model}

In a copolymer system composed of $\mathrm{A}$ and B unit, it is assumed that homopolymer of A unit only have stereoregularity and the sequence distributions of two monomer units and cotacticity of A unit sequence obey Bernoulli, first and second order Markov statistics.

Since homopolymer of B unit has not stereoregularity, cotacticity of diad sequence including B unit cannot be defined, but it is able to consider a kind of stereoregularity of two A units holding sequences of only B unit between them (i.e., $\cdots$ ABA $\cdots$ or $\cdots$ ABBA $\cdots$ ). But since the ${ }^{13} \mathrm{C}$ NMR data suggesting the existence of these structure are not available for the copolymer, the stereoregularity of A unit sequences including no $\mathrm{B}$ units between them is considered.

Note that monomer unit sequence distribution (e.g., $\mathrm{AABAAB}$ ) and its cotacticity distribution (i.e., distribution of cotacticity of the monomer unit sequence, e.g., $m^{* *} r^{*}$, where * means a diad with no cotacticity) may or may not obey the same statistical model, and also monomer unit sequence distribution does or does not correlate with cotacticity distribution. The former case will be referred to as "correlation" and to the latter case as "noncorrelation". In other words, the cotacticity between the growing chain end and the penultimate unit does or does not influence the kind of monomer to be preferentially added at the end, and the monomer unit sequence does or does not effect cotacticity between the newly added monomer unit and the penultimate unit. Statistical models are referred to, e.g., as [1st Markov]-[Bernoulli] (non-correlation) when monomer unit sequence and its cotacticity obey the first order Markov and Bernoulli statistics, respectively and both of these statistics are not correlative to each other. Comeso and coracemo cotacticities are also referred to as $m$ and $r$, respectively.

In sequences including B monomer unit, Markov sequence with cotacticity may stops both sides of B unit, but as a first order approximation the Markov process is regarded to continue.

The statistical models examined in the present article are three cases (thirteen statistics) as below:

\section{Case (1) Non-Correlative Statistical Model}

This case is a combination that each of monomer unit sequence and its cotacticity obeys Bernoulli, first and second order Markov statistics. The number of statistics in the case examined here is nine. Molar fractions of sequences in this case are described as multiplication of a monomer unit sequence expression by a cotacticity one. Detail should be referred in the previous article. ${ }^{16}$

(1.1) [1st Markov]-[Bernoulli] (Non-Correlation) Model. For one example of noncorrelation statistical models, molar fractions 
of pentad sequences with A unit centered in a model [1st Markov]-[Bernoulli] (non-correlation) are described as below, where, e.g., a parameter $P_{(\mathrm{B} / \mathrm{A})}$ is referred to as the probability for the addition of $\mathrm{A}$ unit to growing chain end consisted of $\mathrm{B}$ unit, and $P_{m}$ and $P_{r}$ are referred to as the probability for the comeso and coracemo arrangement, respectively. In this case, relations $P_{(\mathrm{A} / \mathrm{A})}+P_{(\mathrm{B} / \mathrm{A})}=1, P_{(\mathbf{A} / \mathbf{B})}+P_{(\mathrm{B} / \mathrm{B})}$ $=1$ and $P_{m}+P_{r}=1$ are also satisfied, and if three independent parameters are decided and $P_{(\mathrm{B} / \mathrm{A})}+P_{(\mathrm{A} / \mathrm{B})}$ is shortly referred to as $\mathrm{D}^{\mathrm{M}(1)}$ because of first order Markov process in monomer unit sequence, all molar fractions of pentad sequences can be described as the multiplicative products of monomer unit part by cotacticity part. Some examples for molar fractions of pentad sequences with A unit centered are calculated as below:

$$
\begin{aligned}
& \left(\mathrm{A}^{m} \mathrm{~A}^{m} \mathrm{~A}^{m} \mathrm{~A}^{m} \mathrm{~A}\right)= \\
& \left(1-P_{(\mathrm{B} / \mathrm{A})}\right)^{4} P_{(\mathrm{A} / \mathrm{B})} P_{m}{ }^{4} / \mathrm{D}^{\mathrm{M}(1)} \\
& \left(\mathrm{A}^{m} \mathrm{~A}^{m} \mathrm{~A}^{m} \mathrm{AB}\right)= \\
& 2 \mathrm{P}_{(\mathrm{B} / \mathrm{A})}\left(1-P_{(\mathrm{B} / \mathrm{A})}\right)^{3} P_{(\mathrm{A} / \mathrm{B})} P_{m}{ }^{3} / \mathrm{D}^{\mathrm{M}(1)} \\
& \left(\mathrm{ABA}^{r} \mathrm{~A}^{m} \mathrm{~A}\right)= \\
& 2 P_{(\mathrm{B} / \mathrm{A})}\left(1-P_{(\mathrm{B} / \mathrm{A})}\right)^{2} P_{(\mathrm{A} / \mathrm{B})}{ }^{2} P_{m}\left(1-P_{m}\right) / \mathrm{D}^{\mathrm{M}(1)}(5 \mathrm{c}) \\
& \left(\mathrm{A}^{r} \mathrm{~A}^{r} \mathrm{ABB}\right)= \\
& 2 P_{(\mathrm{B} / \mathrm{A})}\left(1-P_{(\mathrm{B} / \mathrm{A})}\right)^{2} P_{(\mathrm{A} / \mathrm{B})}\left(1-P_{(\mathrm{A} / \mathrm{B})}\right)\left(1-P_{m}\right)^{2} \\
& / \mathrm{D}^{\mathrm{M}(1)}
\end{aligned}
$$

\section{Case (2) Correlative Statistical Model}

This case is of correlative combination in which both of monomer unit sequence and its cotacticity obey Bernoulli statistics, and one of them obeys Bernoulli, the other obeys first order Markov statistics. The number of statistical models examined in this case is three, and maximum number of independent parameters are eight in the present article. Details are described as below:

(2.1) [1st Markov]-[Bernoulli] (Correlation) Model. Equations $P_{(m \mathrm{~A} / \mathrm{A})}+P_{(r \mathrm{~A} / \mathrm{A})}+P_{(\mathrm{B} / \mathrm{A})}=1$ and $P_{(\mathrm{A} / \mathrm{B})}+P_{(\mathrm{B} / \mathrm{B})}=1$ are satisfied, and if three independent parameters are given all molar fractions of 36 pentad sequences with A unit centered can be calculated using following equations, where e.g., a parameter $P_{(\mathrm{mA} / \mathbf{B})}$ is referred to as the probability for the comeso addition of $\mathbf{A}$ unit to growing chain end of $\mathbf{B}$ unit:

$$
\begin{aligned}
& \left(\mathrm{A}^{m} \mathrm{~A}^{m} \mathrm{~A}^{m} \mathrm{~A}^{m} \mathrm{~A}\right)=P_{(\mathrm{A} / \mathrm{B})} P_{(m \mathrm{~A} / \mathrm{A})} / \mathrm{D}^{\mathrm{M}(1)} \\
& \left(\mathrm{A}^{m} \mathrm{~A}^{m} \mathrm{~A}^{m} \mathrm{~A}^{r} \mathrm{~A}\right)= \\
& 2 P_{(\mathrm{A} / \mathrm{B})} P_{(m \mathrm{~A} / \mathrm{A})}{ }^{3} P_{(\mathrm{rA} / \mathrm{A})} / \mathrm{D}^{\mathrm{M}(1)}
\end{aligned}
$$

$\left(\mathrm{A}^{r} \mathrm{~A}^{m} \mathrm{~A}^{m} \mathrm{~A}^{r} \mathrm{~A}\right)=$

$$
P_{(\mathrm{A} / \mathrm{B})} P_{(m \mathrm{~A} / \mathrm{A})}{ }^{2} P_{(r \mathrm{~A} / \mathrm{A})}{ }^{2} / \mathrm{D}^{\mathrm{M}(1)}
$$

$\left(A^{m} A^{m} A^{r} A^{m} A\right)=$

$$
2 P_{(\mathrm{A} / \mathrm{B})} P_{(m \mathrm{~A} / \mathrm{A})}{ }^{3} P_{(r \mathrm{~A} / \mathrm{A})} / \mathrm{D}^{\mathrm{M}(1)}
$$

$\left(\mathrm{A}^{m} \mathrm{~A}^{m} \mathrm{~A}^{r} \mathrm{~A}^{r} \mathrm{~A}\right)=$

$$
2 P_{(\mathrm{A} / \mathrm{B})} P_{(m \mathrm{~A} / \mathrm{A})}{ }^{2} P_{(r \mathrm{~A} / \mathrm{A})}{ }^{2} / \mathrm{D}^{\mathrm{M}(1)}
$$

$\left(\mathrm{A}^{r} \mathrm{~A}^{m} \mathrm{~A}^{r} \mathrm{~A}^{m} \mathrm{~A}\right)=$

$$
\begin{aligned}
& 2 P_{(\mathrm{A} / \mathrm{B})} P_{(m \mathrm{~A} / \mathrm{A})}{ }^{2} P_{(r \mathrm{~A} / \mathrm{A})} / \mathrm{D}^{\mathrm{M}(1)} \\
& \left(\mathrm{A}^{r} \mathrm{~A}^{m} \mathrm{~A}^{r} \mathrm{~A}^{r} \mathrm{~A}\right)= \\
& 2 P_{(\mathrm{A} / \mathrm{B})} P_{(m \mathrm{~A} / \mathrm{A})} P_{(r \mathrm{~A} / \mathrm{A})}{ }^{3} / \mathrm{D}^{\mathrm{M}(1)} \\
& \left(\mathrm{A}^{m} \mathrm{~A}^{r} \mathrm{~A}^{r} \mathrm{~A}^{m} \mathrm{~A}\right)= \\
& P_{(\mathrm{A} / \mathrm{B})} P_{(m \mathrm{~A} / \mathrm{A})}{ }^{2} P_{(r \mathrm{~A} / \mathrm{A})} / \mathrm{D}^{\mathrm{M}(1)}
\end{aligned}
$$

$\left(\mathrm{A}^{m} \mathrm{~A}^{r} \mathrm{~A}^{r} \mathrm{~A}^{r} \mathrm{~A}\right)=2 P_{(\mathrm{A} / \mathrm{B})} P_{(m \mathrm{~A} / \mathrm{A})} P_{(r \mathrm{~A} / \mathrm{A})}{ }^{3} / \mathrm{D}^{\mathrm{M}(1)}(6 \mathrm{i})$

$\left(\mathrm{A}^{r} \mathrm{~A}^{r} \mathrm{~A}^{r} \mathrm{~A}^{r} \mathrm{~A}\right)=P_{(\mathrm{A} / \mathrm{B})} P_{(r \mathrm{~A} / \mathrm{A})}{ }^{4} / \mathrm{D}^{\mathrm{M}(1)}$

$\left(\mathrm{A}^{m} \mathrm{~A}^{m} \mathrm{~A}^{m} \mathrm{AB}\right)=2 P_{(\mathrm{A} / \mathrm{B})} P_{(\mathrm{B} / \mathrm{A})} P_{(m \mathrm{~A} / \mathrm{A})}{ }^{3} / \mathrm{D}^{\mathrm{M}(1)}(7 \mathrm{a})$

$\left(\mathrm{A}^{m} \mathrm{~A}^{m} \mathrm{~A}^{r} \mathrm{AB}\right)=$

$$
2 P_{(\mathrm{A} / \mathrm{B})} P_{(\mathrm{B} / \mathrm{A})} P_{(m \mathrm{~A} / \mathrm{A})}{ }^{2} P_{(r \mathrm{~A} / \mathrm{A})} / \mathrm{D}^{\mathrm{M}(1)}
$$

$\left(\mathrm{A}^{m} \mathrm{~A}^{r} \mathrm{~A}^{m} \mathrm{AB}\right)=$

$$
2 P_{(\mathrm{A} / \mathrm{B})} P_{(\mathrm{B} / \mathrm{A})} P_{(m \mathrm{~A} / \mathrm{A})}{ }^{2} P_{(r \mathrm{~A} / \mathrm{A})} / \mathrm{D}^{\mathrm{M}(1)}
$$

$\left(\mathrm{A}^{r} \mathrm{~A}^{m} \mathrm{~A}^{m} \mathrm{AB}\right)=$

$$
2 P_{(\mathrm{A} / \mathrm{B})} P_{(\mathrm{B} / \mathrm{A})} P_{(m \mathrm{~A} / \mathrm{A})}{ }^{2} P_{(r \mathrm{~A} / \mathrm{A})} / \mathrm{D}^{\mathrm{M}(1)}
$$

$\left(\mathrm{A}^{r} \mathrm{~A}^{r} \mathrm{~A}^{m} \mathrm{AB}\right)=$

$$
2 P_{(\mathrm{A} / \mathrm{B})} P_{(\mathrm{B} / \mathrm{A})} P_{(m \mathrm{~A} / \mathrm{A})} P_{(r \mathrm{~A} / \mathrm{A})}{ }^{2} / \mathrm{D}^{\mathrm{M}(1)}
$$

$\left(\mathrm{A}^{r} \mathrm{~A}^{m} \mathrm{~A}^{r} \mathrm{AB}\right)=$

$$
2 P_{(\mathrm{A} / \mathrm{B})} P_{(\mathrm{B} / \mathrm{A})} P_{(m \mathrm{~A} / \mathrm{A})} P_{(r \mathrm{~A} / \mathrm{A})}{ }^{2} / \mathrm{D}^{\mathrm{M}(1)}
$$

$\left(A^{m} A^{r} A^{r} A B\right)=$ 


$$
\begin{aligned}
& 2 P_{(\mathrm{A} / \mathrm{B})} P_{(\mathrm{B} / \mathrm{A})} P_{(m \mathrm{~A} / \mathrm{A})} P_{(\mathrm{rA} / \mathrm{A})}{ }^{2} / \mathrm{D}^{\mathrm{M}(1)} \\
& \left(\mathrm{A}^{r} \mathrm{~A}^{r} \mathrm{~A}^{r} \mathrm{AB}\right)=2 P_{(A / B)} P_{(\mathrm{B} / \mathrm{A})} P_{(\mathrm{rA} / \mathrm{A})}{ }^{3} / \mathrm{D}^{\mathrm{M}(1)} \\
& \left(\mathrm{ABA}^{m} \mathrm{~A}^{m} \mathrm{~A}\right)=2 P_{(\mathrm{A} / \mathrm{B})}{ }^{2} P_{(\mathrm{B} / \mathrm{A})} P_{(m \mathrm{~A} / \mathrm{A})}{ }^{2} / \mathrm{D}^{\mathrm{M}(1)}(8 \mathrm{a}) \\
& \left(\mathrm{ABA}^{m} \mathrm{~A}^{r} \mathrm{~A}\right)= \\
& 2 P_{(\mathrm{A} / \mathrm{B})}{ }^{2} P_{(\mathrm{B} / \mathrm{A})} P_{(m \mathrm{~A} / \mathrm{A})} P_{(\mathrm{rA} / \mathrm{A})} / \mathrm{D}^{\mathrm{M}(1)} \\
& \left(\mathrm{ABA}^{r} \mathrm{~A}^{m} \mathrm{~A}\right)= \\
& 2 P_{(\mathrm{A} / \mathrm{B})}{ }^{2} P_{(\mathrm{B} / \mathrm{A})} P_{(m \mathrm{~A} / \mathrm{A})} P_{(\mathrm{rA} / \mathrm{A})} / \mathrm{D}^{\mathrm{M}(1)} \\
& \left(\mathrm{ABA}^{r} \mathrm{~A}^{r} \mathrm{~A}\right)=2 P_{(\mathrm{A} / \mathrm{B})}{ }^{2} P_{(\mathrm{B} / \mathrm{A})} P_{(\mathrm{rA} / \mathrm{A})}{ }^{2} / \mathrm{D}^{\mathrm{M}(1)} \\
& \left(\mathrm{A}^{m} \mathrm{~A}^{m} \mathrm{ABB}\right)= \\
& 2 P_{(\mathrm{A} / \mathrm{B})} P_{(\mathrm{B} / \mathrm{A})} P_{(\mathrm{B} / \mathrm{B})} P_{(m \mathrm{~A} / \mathrm{A})}{ }^{2} / \mathrm{D}^{\mathrm{M}(1)} \\
& \left(\mathrm{A}^{m} \mathrm{~A}^{r} \mathrm{ABB}\right)= \\
& 2 P_{(\mathrm{A} / \mathrm{B})} P_{(\mathrm{B} / \mathrm{A})} P_{(\mathrm{B} / \mathrm{B})} P_{(m \mathrm{~A} / \mathrm{A})} P_{(r \mathrm{~A} / \mathrm{A})} / \mathrm{D}^{\mathrm{M}(1)} \\
& \left(\mathrm{A}^{r} \mathrm{~A}^{m} \mathrm{ABB}\right)= \\
& 2 P_{(\mathrm{A} / \mathrm{B})} P_{(\mathrm{B} / \mathrm{A})} P_{(\mathrm{B} / \mathrm{B})} P_{(m \mathrm{~A} / \mathrm{A})} P_{(\mathrm{rA} / \mathrm{A})} / \mathrm{D}^{\mathrm{M}(1)} \\
& \left(\mathrm{A}^{r} \mathrm{~A}^{r} \mathrm{ABB}\right)= \\
& 2 P_{(\mathrm{A} / \mathrm{B})} P_{(\mathrm{B} / \mathrm{A})} P_{(\mathrm{B} / \mathrm{B})} P_{(\mathrm{rA} / \mathrm{A})}{ }^{2} / \mathrm{D}^{\mathrm{M}(1)} \\
& \left(\mathrm{BA}^{m} \mathrm{~A}^{m} \mathrm{AB}\right)=P_{(\mathrm{A} / \mathrm{B})} P_{(\mathrm{B} / \mathrm{A})}{ }^{2} P_{(m \mathrm{~A} / \mathrm{A})}{ }^{2} / \mathrm{D}^{\mathrm{M}(1)} \\
& \left(\mathrm{BA}^{m} \mathrm{~A}^{r} \mathrm{AB}\right)= \\
& 2 P_{(\mathrm{A} / \mathrm{B})} P_{(\mathrm{B} / \mathrm{A})}{ }^{2} P_{(m \mathrm{~A} / \mathrm{A})} P_{(\mathrm{rA} / \mathrm{A})} / \mathrm{D}^{\mathrm{M}(1)} \\
& \left(\mathrm{BA}^{r} \mathrm{~A}^{r} \mathrm{AB}\right)=P_{(\mathrm{A} / \mathrm{B})} P_{(\mathrm{B} / \mathrm{A})}{ }^{2} P_{(\mathrm{rA} / \mathrm{A})}{ }^{2} / \mathrm{D}^{\mathrm{M}(1)} \\
& \left(\mathrm{ABA}^{m} \mathrm{AB}\right)=2 P_{(\mathrm{A} / \mathrm{B})}{ }^{2} P_{(\mathrm{B} / \mathrm{A})}{ }^{2} P_{(m \mathrm{~A} / \mathrm{A})} / \mathrm{D}^{\mathrm{M}(1)} \\
& \left(\mathrm{ABA}^{r} \mathrm{AB}\right)=2 P_{(\mathrm{A} / \mathrm{B})}{ }^{2} P_{(\mathrm{B} / \mathrm{A})}{ }^{2} P_{(r \mathrm{~A} / \mathrm{A})} / \mathrm{D}^{\mathrm{M}(1)} \\
& \left(\mathrm{BBA}^{m} \mathrm{AB}\right)= \\
& 2 P_{(\mathrm{A} / \mathrm{B})} P_{(\mathrm{B} / \mathrm{A})}{ }^{2} P_{(\mathrm{B} / \mathrm{B})} P_{(m \mathrm{~A} / \mathrm{A})} / \mathrm{D}^{\mathrm{M}(1)} \\
& \left(\mathrm{BBA}^{r} \mathrm{AB}\right)= \\
& 2 P_{(\mathrm{A} / \mathrm{B})} P_{(\mathrm{B} / \mathrm{A})}{ }^{2} P_{(\mathrm{B} / \mathrm{B})} P_{(\mathrm{rA} / \mathrm{A})} / \mathrm{D}^{\mathrm{M}(1)} \\
& (\mathrm{ABABA})=P_{(\mathrm{A} / \mathrm{B})}{ }^{3} P_{(\mathrm{B} / \mathrm{A})}{ }^{2} / \mathrm{D}^{\mathrm{M}(1)} \\
& (\mathrm{ABABB})=2 P_{(\mathrm{A} / \mathrm{B})}{ }^{2} P_{(\mathrm{B} / \mathrm{A})}{ }^{2} P_{(\mathrm{B} / \mathrm{B})} / \mathrm{D}^{\mathrm{M}(1)} \\
& (\mathrm{BBABB})=P_{(\mathrm{A} / \mathrm{B})} P_{(\mathrm{B} / \mathrm{A})}{ }^{2} P_{(\mathrm{B} / \mathrm{B})}{ }^{2} / \mathrm{D}^{\mathrm{M}(1)}
\end{aligned}
$$

(2.2) [Bernoulli]-[1st Markov] (Correlation) Model. The another statistics sample of the case is [Bernoulli]-[1st Markov] (correlation), in which in order to express cotacticity sequence distribution as the first order Markov statistics it becomes needed to deal with the growing end and penultimate consisted of AA. Consequently, the expression of monomer unit sequence distribution of this statistics becomes inevitably the second order Markov statistics, so this means that the statistics is [2nd Markov]-[1st Markov] (correlation). The basic equations among the probability parameters are:

$$
\begin{aligned}
& P_{(m \mathrm{~A} / m)}+P_{(r \mathrm{~A} / m)}+P_{(\mathrm{B} / m)}=1 \\
& P_{(m \mathrm{AA} / r)}+P_{(r \mathrm{~A} / r)}+P_{(\mathrm{B} / r)}=1 \\
& P_{(m \mathrm{AA} / \mathrm{BA})}+P_{(\mathrm{rA} / \mathrm{BA})}+P_{(\mathrm{B} / \mathrm{BA})}=1 \\
& P_{(\mathrm{A} / \mathrm{AB})}+P_{(\mathrm{B} / \mathrm{AB})}=1 \\
& P_{(\mathrm{A} / \mathrm{BB})}+P_{(\mathrm{B} / \mathrm{BB})}=1
\end{aligned}
$$

where eight parameters are independent. If parameters $\mathrm{D}^{\mathrm{M}(2)^{*} m r(1)}, X_{m}, X_{r}$, and $Y_{m r}$ are defined by the relations,

$$
\begin{aligned}
& \mathrm{D}^{\mathrm{M}(2)^{*} m r(1)}= \\
& \left\{\left(1-P_{(m \mathrm{~A} / m)}\right)\left(1-P_{(r \mathrm{~A} / r)}\right)-P_{(m \mathrm{~A} / r)} P_{(r \mathrm{~A} / m)}\right\} \\
& \quad \times\left(2+P_{(\mathrm{B} / \mathrm{AB})} / P_{(\mathrm{A} / \mathrm{BB})}\right) \\
& +P_{(\mathrm{rA} / \mathrm{BA})}\left(1+P_{(m \mathrm{~A} / r)}-P_{(m \mathrm{~A} / m)}\right) \\
& +P_{(m \mathrm{AA} / \mathrm{BA})}\left(1+P_{(r \mathrm{~A} / m)}-P_{(r \mathrm{~A} / r)}\right) \\
& \mathrm{X}_{m}=P_{(m \mathrm{~A} / r)} P_{(r \mathrm{AA} / \mathrm{BA})}+P_{(m \mathrm{~A} / \mathrm{BA})}\left(1-P_{(r \mathrm{~A} / r)}\right) \\
& \mathrm{X}_{r}=P_{(r \mathrm{~A} / m)} P_{(m \mathrm{AA} / \mathrm{BA})}+P_{(r \mathrm{~A} / \mathrm{BA})}\left(1-P_{(m \mathrm{~A} / m)}\right) \\
& \mathrm{Y}_{m r}=\left(1-P_{(m \mathrm{~A} / m)}\right)\left(1-P_{(r \mathrm{~A} / r)}\right) \\
& \quad-P_{(m \mathrm{~A} / r)} P_{(r \mathrm{~A} / m)}
\end{aligned}
$$

four diads can be written in the forms:

$$
\begin{aligned}
& \left(\mathrm{A}^{m} \mathrm{~A}\right)=\mathrm{X}_{m} / \mathrm{D}^{\mathrm{M}(2)^{*} m r(1)} \\
& \left(\mathrm{A}^{r} \mathrm{~A}\right)=\mathrm{X}_{r} / \mathrm{D}^{\mathrm{M}(2)^{*} m r(1)} \\
& (\mathrm{AB})=2 \mathrm{Y}_{m r} / \mathrm{D}^{\mathrm{M}(2)^{*} m r(1)} \\
& (\mathrm{BB})=\left(P_{(\mathrm{B} / \mathrm{AB})} / P_{(\mathrm{A} / \mathrm{BB})}\right) \mathrm{Y}_{m r} / \mathrm{D}^{\mathrm{M}(2)^{*} m r(1)}
\end{aligned}
$$

and all molar fractions of 36 pentad sequences with A unit centered will be shown in APPENDIX B (2.2).

\section{Case (3) $\sigma$-Parameter Model}

For a long time Bovey's statistics, which first 
introduced cotacticity parameter $\sigma^{1}$, has been employed most widely for copolymer sequence distribution and all of its 20 triads were compiled by Klesper and Sielaff. ${ }^{18}$ But it is regrettable that eq (137)-(141) in their compilation include some mistakes. In the present article, the Bovey's statistics has been extended to a new statistics for another copolymer system in which homopolymer of one monomer unit only have stereoregularity. This statistics newly extended is also referred to as s-parameter model as same as in the previous article. A parameter $\sigma_{\mathrm{AA}}$ is referred to the probability of the comeso arrangement in A-A diad sequence. Since the homopolymer consisted of only B unit has no stereoregularity, parameters $\sigma_{\mathrm{AB}}, \sigma_{\mathrm{BA}}$, and $\sigma_{\mathrm{BB}}$ do not exist.

This statistics is a case in which both distributions of monomer unit sequence and its cotacticity correlate to each other, and the former is dealt as almost the first order Markov statistics and the latter Bernoulli. Since cotacticity in this model depends only on the monomer unit diad sequence, the model corresponds to [1st Markov]-[Bernoulli] (correlation) in case (2) and [1st Markov][Bernoulli] (correlation) can be reduced to this Bovey's model if following equations are employed;

$$
\begin{aligned}
& P_{(m \mathrm{~A} / \mathrm{A})}=P_{(\mathrm{A} / \mathrm{A})} \sigma_{\mathrm{AA}} \\
& P_{(m \mathrm{~B} / \mathrm{A})}=P_{(\mathrm{B} / \mathrm{A})} \sigma_{\mathrm{AB}} \\
& P_{(m \mathrm{~A} / \mathrm{B})}=P_{(\mathrm{A} / \mathrm{B})} \sigma_{\mathrm{BA}} \\
& P_{(m \mathrm{~B} / \mathrm{B})}=P_{(\mathrm{B} / \mathrm{B})} \sigma_{\mathrm{BB}} \\
& P_{\mathrm{A}}=P_{(\mathrm{A} / \mathrm{B})} /\left(P_{(\mathrm{A} / \mathrm{B})}+P_{(\mathrm{B} / \mathrm{A})}\right) \\
& P_{\mathrm{AA}}=P_{(\mathrm{A} / \mathrm{A})}
\end{aligned}
$$

Therefore, Bovey's statistical model can be regarded as a special case of [1st Markov][Bernoulli] (correlation). But because of the style to be expressed as central monomer unit, there exist following problems:

1) The model cannot express reasonably the sequences consisted of even number of monomer units.

2) Since the model cannot describe the sequences which proceed to one direction, it cannot express exactly Markov processes.

But this model has been widely used by many scientists, so in the present article it have been examined comparing with the strict Markov models.

Two equations $P_{(\mathrm{A} / \mathrm{A})}+P_{(\mathbf{B} / \mathbf{A})}=1$ and $P_{(\mathbf{A} / \mathbf{B})}+$ $P_{(\mathrm{B} / \mathrm{B})}=1$ also hold in this model. Besides two independent parameters in these equations, $P_{\mathrm{A}}$ and $\sigma_{\mathrm{AA}}$ can be taken as independent parameters, where e.g., a parameter $P_{\mathrm{A}}$ is referred to the probability for addition of $A$ unit to growing chain end. $P_{\mathrm{A}}$ can be calculated directly from intensities of carbon peaks incorporated in each monomer unit of $\mathrm{A}$ and $B$ using ${ }^{13} \mathrm{C}$ NMR equipment. Some examples for molar fractions of pentad sequences with $\mathrm{A}$ unit centered will be also shown in APPENDIX B(3).

Case (1) and (2) are ones which obey exactly the notion of Markov statistics, and case (3) is another one which has been used widely hitherto but is not within Markovian category. All of them do not have more than eight independent parameters. Table $\mathrm{V}$ lists probability parameters belonging to each statistics model.

\section{Selection of the Most Suitable Statistical Model}

Similarly to the previous paper, ${ }^{16}$ the probability parameters for each statistical model are calculated using electronic computer to minimize the parameter $\delta^{\prime}$ in following equation:

$$
\delta^{\prime}=\frac{\sqrt{\sum_{i=1}^{N}\left(X_{i}-Y_{i}\right)^{2}}}{N},
$$

where $X_{i}$ and $Y_{i}$ are the experimental and calculated molar fractions for a specific triad sequence, respectively, and $N$ is the total number of independent molar fraction data to be calculated. The minimized value of $\delta^{\prime}$ is 
Table V. Statistical Probabilities generating monomer unit sequence and cotacticity

\begin{tabular}{|c|c|c|c|c|c|c|}
\hline \multirow{3}{*}{$\begin{array}{l}\text { Monomer unit } \\
\text { sequence }\end{array}$} & \multicolumn{6}{|c|}{ Cotacticity } \\
\hline & \multicolumn{2}{|c|}{ Bernoulli } & \multicolumn{2}{|c|}{ 1st Markov } & \multicolumn{2}{|c|}{ 2nd Markov } \\
\hline & Non-correlation & Correlation & Non-correlation & Correlation & Non-correlation & Correlation \\
\hline Bernoulli & $\begin{array}{l}P_{m}, P_{\mathrm{r}} \\
P_{\mathrm{A}}, P_{\mathrm{B}} \\
\\
\quad 4^{\mathrm{a}(2)^{\mathrm{b}}}\end{array}$ & $\begin{array}{l}P_{m \mathrm{~A}} \\
P_{\mathrm{rA}} \\
P_{\mathrm{B}}\end{array}$ & $\begin{array}{l}P_{(m / m)}, P_{(r / m)} \\
P_{(m / r)}, P_{(r / r)} \\
P_{\mathrm{A}}, P_{\mathrm{B}}\end{array}$ & $\begin{array}{l}P_{(m \mathrm{~A} / m)}, P_{(r \mathrm{~A} / m)} \\
P_{(m \mathrm{~A} / r)}, P_{(r \mathrm{~A} / r)} \\
P_{(\mathrm{B} / m)}, P_{(\mathrm{B} / r)}\end{array}$ & $\begin{array}{c}P_{(m / m m)}, P_{(r / m m)} \\
P_{(m / m r)}, P_{(r / m r)} \\
P_{(m / r m)}, P_{(r / r m)} \\
P_{(m / r r)}, P_{(r / r r)} \\
P_{\mathrm{A}}, P_{\mathrm{B}} \\
\quad 10(5)\end{array}$ & Not calculated \\
\hline 1st Markov & $\begin{array}{l}P_{m}, P_{r} \\
P_{(\mathrm{A} / \mathrm{A})}, P_{(\mathbf{B} / \mathrm{A})} \\
P_{(\mathrm{A} / \mathbf{B})}, P_{(\mathbf{B} / \mathbf{B})}\end{array}$ & $\begin{array}{l}P_{(m \mathbf{A} / \mathbf{A})} \\
P_{(r \mathbf{A} / \mathbf{A})} \\
P_{(\mathbf{B} / \mathbf{A})} \\
P_{(\mathbf{A} / \mathbf{B})} \\
P_{(\mathbf{B} / \mathbf{B})} \\
\quad 5(3)\end{array}$ & $\begin{array}{l}P_{(m / m)}, P_{(r / m)} \\
P_{(m / r)}, P_{(r / r)} \\
P_{(\mathrm{A} / \mathrm{A})}, P_{(\mathrm{B} / \mathrm{A})} \\
P_{(\mathrm{A} / \mathrm{B})}, P_{(\mathrm{B} / \mathbf{B})}\end{array}$ & Not calculated & $\begin{array}{c}P_{(m / m m)}, P_{(r / m m)} \\
P_{(m / m r)}, P_{(r / m r)} \\
P_{(m / r m)}, P_{(r / r m)} \\
P_{(m / r r)}, P_{(r / r r)} \\
P_{(\mathbf{A} / \mathbf{A})}, P_{(\mathbf{B} / \mathbf{A})} \\
P_{(\mathbf{A} / \mathbf{B})}, P_{(\mathbf{B} / \mathbf{B})} \\
12(6)\end{array}$ & Not calculated \\
\hline 2nd Markov & $\begin{array}{l}P_{m}, P_{r} \\
P_{(\mathrm{A} / \mathrm{AA})}, P_{(\mathbf{B} / \mathrm{AA})} \\
P_{(\mathrm{A} / \mathrm{AB})}, P_{(\mathbf{B} / \mathrm{AB})} \\
P_{(\mathrm{A} / \mathrm{BA})}, P_{(\mathbf{B} / \mathbf{B A})} \\
P_{(\mathrm{A} / \mathrm{BB})}, P_{(\mathbf{B} / \mathbf{B B})}\end{array}$ & & $\begin{array}{l}P_{(m / m)}, P_{(r / m)} \\
P_{(m / r)}, P_{(r / r)} \\
P_{(\mathrm{A} / \mathrm{AA})}, P_{(\mathrm{B} / \mathrm{AA})} \\
P_{(\mathrm{A} / \mathrm{AB})}, P_{(\mathrm{B} / \mathrm{AB})} \\
P_{(\mathrm{A} / \mathrm{BA})}, P_{(\mathrm{B} / \mathrm{BA})} \\
P_{(\mathrm{A} / \mathrm{BB})}, P_{(\mathrm{B} / \mathrm{BB})}\end{array}$ & Not calculated & $\begin{array}{c}P_{(m / m m)}, P_{(r / m m)} \\
P_{(m / m r)}, P_{(r / m r)} \\
P_{(m / r m)}, P_{(r / r m)} \\
P_{(m / r r)}, P_{(r / r r)} \\
P_{(\mathrm{A} / \mathrm{AA})}, P_{(\mathrm{B} / \mathrm{AA})} \\
P_{(\mathrm{A} / \mathrm{AB})}, P_{(\mathbf{B} / \mathrm{AB})} \\
P_{(\mathrm{A} / \mathrm{BA})}, P_{(\mathrm{B} / \mathrm{BA})} \\
P_{(\mathrm{A} / \mathrm{BB})}, P_{(\mathrm{B} / \mathrm{BB})} \\
16(8)\end{array}$ & Not calculated \\
\hline
\end{tabular}

${ }^{a}$ Total number of parameters in a given statistical model. ${ }^{b}$ Number of independent parameters.

referred to as $\delta_{\min }^{\prime}$ for each statistical model.

Every value of $\delta_{\text {min }}^{\prime}$ for each statistical model was compared to select the most suitable statistical model which has the least value of $\delta_{\min }^{\prime}$. In order to analyze by means of this method, it is needed that the number of independent fraction data is larger than that of independent parameters of statistical model. Since a criterion as a function of many variables has generally a possibility to possess many local minima, it was tried to search optimum by maximum gradient method after estimating the criterion at every lattice point divided into ten equal parts for each parameter to ascertain the whole curved surface.

This method is an extension of the method by Kamide et al., ${ }^{19}$ who proposed to examine the sequence distribution of stereoregularity of polyacrylonitrile.

\section{EXPERIMENTAL}

The copolymer used for analysis in this study was synthesized azeotropically by the method of solution polymerization in dimethylformamide under nitrogen atmosphere using azobisisobutylonitrile as an initiator as reported by Yamazaki et al. ${ }^{15}$ The feed ratio of $\mathrm{AN}$ to $\mathrm{VdCl}_{2}$ is 72 to 28 in molar percent. The ${ }^{13} \mathrm{C}$ NMR measurement was carried out in the mixture of dimethyl sulfoxide and deuterated dimethyl sulfoxide at $80^{\circ} \mathrm{C}$ using FX-200 (200 MHz- ${ }^{1} \mathrm{H}\left\{{ }^{13} \mathrm{C}\right\}$ NMR) equipped by JEOL. Detailed conditions are to be referred to the 
literature.

\section{RESULTS AND DISCUSSION}

Though there have been many studies ${ }^{20-22}$ on monomer unit sequence distributions for poly(acrylonitrile-co-vinylidene chloride), no article can be seen without Yamazaki et al. ${ }^{15}$ who analyzed exhaustively all the pentad monomer unit sequences combined with cotacticity about the copolymer.

Table VI cites the data of nitrile and methine region of ${ }^{13} \mathrm{C}$ NMR observed for poly(acrylonitrile-co-vinylidene chloride) by Yamazaki et al. ${ }^{15}$ Here, analytical calculations were carried out using intensity data of AN unit centered pentad fractions. Therefore the intensity data of 14 and 13 envelopes for nitrile and methine carbon, respectively, were employed in all the $36 \mathrm{AN}$ unit centered pentads because of peak overlapping or poor resolution.

Table VII compiles the values of parameter $\delta_{\min }^{\prime}$ as the results of analysis using the data reported by Yamazaki et al. through use of the method proposed in the present article. On the whole, the values of parameter $\delta_{\min }^{\prime}$ do not exceed largely than 0.005 . Even a model described only by two Bernoulli statistics can explain the sequence distribution of the copolymer perhaps because of radical preparation. The most adequate model to explain the sequence distribution of the copolymer combined with cotacticity is [2nd Markov]-[2nd Markov] (non-correlation) from both analysis of nitrile and methine carbon data.

Values of parameter $\delta_{\text {min }}^{\prime}$ for corresponding correlative and non-correlative statistical models agree with each other for the copolymer. In other words for example, two values of $\delta_{\text {min }}^{\prime}$ of [1st Markov]-[Bernoulli] (non-correlation) and [1st Markov]-[Bernoulli] (correlation) accord with each other. These results suggest that there does not exist the difference between correlation and non-correlation models, and therefore that monomer unit sequence and its cotacticity do not correlate with each other. In the results of analysis data of methine carbon, however, four models in non-correlation model and two in correlation model give values of $\delta_{\text {min }}^{\prime}$ in a range of $4.97-4.99$, and differences in values of $\delta_{\text {min }}^{\prime}$ between every models are very small in all models calculated.

Table VIII collects the values of addition probability parameters of [2nd Markov]-[2nd Markov] (non-correlation), which is the most adequate statistical model. Here, the results for methine carbon data show that there exist plural solutions for probability parameters which give the same $\delta_{\min }^{\prime}$, consequently still more progress of resolutionability of NMR technology should be required in order to obtain the exact values of probability parameters attributed to actual phenomenon.

There exist following relations between Bernoulli, first and second order Markov statistical probabilities, ${ }^{23}$ being able to obtain statistical probabilities reduced from that of higher order Markov statistics:

$$
\begin{aligned}
& P_{m}=P_{(m / r)} /\left(P_{(r / m)}+P_{(m / r)}\right) \\
& P_{(r / m)}=P_{(r / m m)} /\left(P_{(r / m m)}+P_{(m / r m)}\right) \\
& P_{(m / r)}=P_{(m / r r)} /\left(P_{(r / m r)}+P_{(m / r r)}\right)
\end{aligned}
$$

Similarly to this, for the probability parameters of monomer unit sequence distribution, the relations hold:

$$
\begin{aligned}
& P_{\mathrm{N}}=P_{(\mathrm{N} / \mathrm{V})} /\left(P_{(\mathrm{V} / \mathrm{N})}+P_{(\mathrm{N} / \mathrm{V})}\right) \\
& P_{(\mathrm{V} / \mathrm{N})}=P_{(\mathrm{V} / \mathrm{NN})} /\left(P_{(\mathrm{V} / \mathrm{NN})}+P_{(\mathrm{N} / \mathrm{VN})}\right) \\
& P_{(\mathrm{N} / \mathrm{V})}=P_{(\mathrm{N} / \mathrm{VV})} /\left(P_{(\mathrm{V} / \mathrm{NV})}+P_{(\mathrm{N} / \mathrm{VV})}\right)
\end{aligned}
$$

The values of first order Markov statistical parameters obtained using eq (22) from second order Markov parameters are $P_{(\mathrm{V} / \mathrm{N})}=0.354$, $P_{(\mathrm{N} / \mathrm{V})}=0.745$ for nitrile carbon and $P_{(\mathrm{V} / \mathrm{N})}=$ $0.306, P_{(\mathrm{N} / \mathrm{V})}=0.827$ for methine carbon, showing that they are very close to the data, $P_{\mathrm{NV}}=P_{(\mathrm{V} / \mathrm{N})}=0.31$ and $P_{\mathrm{VN}}=P_{(\mathrm{N} / \mathrm{V})}=0.8 \mathrm{re}-$ ported by Yamazaki et al. ${ }^{15}$ Equation 21 and the analysis of ${ }^{13} \mathrm{C}$ NMR spectra for nitrile and methine carbon leads to $P_{\mathrm{N}}=0.678$ and 


\section{K. Hisatani, K. Okajima, and K. Kamide}

Table VI. Mol fractions of pentads with cotacticity for poly(acrylonitrile(N)-co-vinylidene chloride(V)) cited from literature 4

\begin{tabular}{|c|c|c|c|c|c|}
\hline \multicolumn{3}{|c|}{$\mathrm{CN}$ carbon } & \multicolumn{3}{|c|}{$\mathrm{CH}$ carbon } \\
\hline Pentad sequence & $\begin{array}{l}\text { Chemical } \\
\text { shift/ppm }\end{array}$ & $\begin{array}{l}\text { Observed } \\
\text { fraction }\end{array}$ & Pentad sequence & $\begin{array}{l}\text { Chemical } \\
\text { shift/ppm }\end{array}$ & $\begin{array}{c}\text { Observed } \\
\text { fraction }\end{array}$ \\
\hline VVNVV & 121.30 & 0.011 & \multirow{3}{*}{$\begin{array}{l}\mathrm{N}^{r} \mathrm{~N}^{r} \mathrm{~N}^{r} \mathrm{~N}^{r} \mathrm{~N}^{\mathrm{a}} \\
\mathrm{N}^{r} \mathrm{~N}^{r} \mathrm{~N}^{r} \mathrm{~N}^{m} \mathrm{~N}^{\mathrm{b}} \\
\mathrm{N}^{m} \mathrm{~N}^{r} \mathrm{~N}^{r} \mathrm{~N}^{m} \mathrm{~N}\end{array}$} & $\begin{array}{l}27.88 \\
27.88\end{array}$ & \multirow{3}{*}{0.065} \\
\hline & & 0031 & & $\begin{array}{l}27.88 \\
27.88\end{array}$ & \\
\hline ender & 121.10 & 0.051 & & & \\
\hline \multirow[t]{2}{*}{ NVNVN } & \multirow[t]{2}{*}{121.03} & \multirow[t]{2}{*}{0.076} & \multirow{2}{*}{$\begin{array}{l}\text { VNr } N^{r} N^{r} N \\
V^{r} N^{r} N^{m} N\end{array}$} & \multirow{2}{*}{$\begin{array}{l}27.77 \\
27.77\end{array}$} & \multirow{2}{*}{0.043} \\
\hline & & & & & \\
\hline \multirow{2}{*}{$\begin{array}{l}V_{V N}^{m} N^{m} N \\
V^{m} N^{m} N V\end{array}$} & 120.70 & \multirow{2}{*}{0.031} & \multirow[b]{2}{*}{$\mathrm{VN}^{r} \mathrm{~N}^{r} \mathrm{NV}$} & & \multirow[b]{2}{*}{0.009} \\
\hline & 120.70 & & & 27.70 & \\
\hline $\mathrm{NVN}^{m} \mathrm{NV}$ & 120.60 & \multirow{4}{*}{0.087} & \multirow{6}{*}{$\begin{array}{l}\mathrm{N}^{r} \mathrm{~N}^{r} \mathrm{~N}^{m} \mathrm{~N}^{r} \mathrm{~N} \\
\mathrm{~N}^{m} \mathrm{~N}^{r} \mathrm{~N}^{m} \mathrm{~N}^{r} \mathrm{~N} \\
\mathrm{~N}^{r} \mathrm{~N}^{r} \mathbf{N}^{m} \mathrm{~N}^{m} \mathrm{~N} \\
\mathrm{~N}^{m} \mathrm{~N}^{r} \mathrm{~N}^{m} \mathrm{~N}^{m} \mathrm{~N} \\
\mathrm{VN}^{r} \mathrm{~N}^{m} \mathrm{~N}^{r} \mathrm{~N} \\
\mathrm{VN}^{r} \mathrm{~N}^{m} \mathrm{~N}^{m} \mathrm{~N}\end{array}$} & 27.42 & \multirow{6}{*}{0.181} \\
\hline $\mathrm{NVN}^{m} \mathrm{~N}^{m} \mathrm{~N}$ & 120.60 & & & 27.42 & \\
\hline $\mathrm{VVN}^{m} \mathrm{~N}^{r} \mathrm{~N}$ & 120.60 & & & \multirow{2}{*}{$\begin{array}{l}27.42 \\
27.42\end{array}$} & \\
\hline & & & & & \\
\hline \multirow[t]{2}{*}{$N_{V} N^{m} N^{r} N$} & 120.49 & \multirow[t]{2}{*}{0.087} & & 27.42 & \\
\hline & & & & 27.42 & \\
\hline$N^{m} N^{m} N^{m} N^{m} N$ & 120.28 & & & & \\
\hline $\mathrm{VN}^{m} \mathrm{~N}^{m} \mathrm{~N}^{m} \mathrm{~N}$ & 120.28 & 0.037 & $\mathrm{~N}^{r} \mathrm{~N}^{r} \mathrm{~N}^{m} \mathrm{NV}$ & 27.25 & \\
\hline $\mathrm{VN}^{m} \mathrm{~N}^{m} \mathrm{NV}$ & 120.28 & & $\mathrm{~N}^{m} \mathrm{~N}^{r} \mathrm{~N}^{m} \mathrm{NV}$ & 27.25 & 0.065 \\
\hline & & & $\mathrm{VN}^{r} \mathrm{~N}^{m} \mathrm{NV}$ & 27.25 & \\
\hline $\mathrm{N}^{r} \mathrm{~N}^{m} \mathrm{~N}^{m} \mathrm{~N}^{m} \mathrm{~N}$ & 120.15 & & & & \\
\hline $\mathrm{VN}^{m} \mathrm{~N}^{m} \mathrm{~N}^{r} \mathrm{~N}$ & 120.15 & & $N^{r} N^{m} N^{m} N^{r} N$ & 26.90 & \\
\hline $\mathrm{VVN}^{r} \mathrm{~N}^{m} \mathrm{~N}$ & 120.15 & & $\mathrm{~N}^{r} \mathrm{~N}^{m} \mathrm{~N}^{m} \mathrm{~N}^{m} \mathrm{~N}$ & 26.90 & 0.072 \\
\hline$V_{V N}^{r} N V$ & 120.15 & 0.105 & $N^{m} N^{m} N^{m} N^{m} N$ & 26.90 & \\
\hline $\mathrm{N}^{r} \mathrm{~N}^{m} \mathrm{~N}^{m} \mathrm{~N}^{r} \mathrm{~N}$ & 120.15 & & & & \\
\hline$V_{V N}^{r} N^{r} \mathrm{~N}$ & 120.15 & & $\mathrm{VN}^{m} \mathrm{~N}^{m} \mathrm{~N}^{r} \mathrm{~N}$ & 26.80 & 0.053 \\
\hline $\mathrm{NVN}^{r} \mathrm{~N}^{r} \mathrm{~N}$ & 120.05 & & $\mathrm{VN}^{m} \mathrm{~N}^{m} \mathrm{~N}^{m} \mathrm{~N}$ & 26.80 & \\
\hline$N_{V N} N^{m} N$ & 120.05 & 0.188 & $\mathrm{VN}^{m} \mathrm{~N}^{m} \mathrm{NV}$ & 26.75 & 0.010 \\
\hline $\mathrm{NVN}^{r} \mathrm{NV}$ & 120.05 & & & & \\
\hline & & & $\mathrm{NVN}^{r} \mathrm{~N}^{r} \mathrm{~N}$ & 26.30 & \\
\hline $\mathrm{N}^{m} \mathrm{~N}^{r} \mathrm{~N}^{m} \mathrm{~N}^{m} \mathrm{~N}$ & 119.80 & & $\mathrm{NVN}^{r} \mathrm{~N}^{m} \mathrm{~N}$ & 26.30 & \\
\hline$V^{r} N^{m} N^{m} N$ & 119.80 & & $\mathrm{VVN}^{r} \mathrm{~N}^{r} \mathrm{~N}$ & 26.30 & 0.194 \\
\hline $\mathrm{N}^{m} \mathrm{~N}^{r} \mathrm{~N}^{m} \mathrm{NV}$ & 119.80 & 0.091 & $V_{V N} N^{m} \mathbf{N}$ & 26.30 & \\
\hline $\mathrm{VN}^{r} \mathrm{~N}^{m} \mathrm{NV}$ & 119.80 & & $\mathrm{NVN}^{r} \mathrm{NV}$ & 26.30 & \\
\hline $\mathrm{N}^{m} \mathrm{~N}^{r} \mathrm{~N}^{m} \mathrm{~N}^{r} \mathrm{~N}$ & 119.72 & & VVN'NV & 26.15 & 0.008 \\
\hline $\mathrm{N}^{r} \mathrm{~N}^{r} \mathrm{~N}^{m} \mathrm{~N}^{m} \mathrm{~N}$ & 119.72 & & & & \\
\hline $\mathrm{N}^{r} \mathrm{~N}^{r} \mathrm{~N}^{m} \mathrm{NV}$ & 119.72 & 0.144 & $\mathrm{NVN}^{m} \mathrm{~N}^{r} \mathrm{~N}$ & 25.80 & \\
\hline $\mathrm{VN}^{r} \mathrm{~N}^{m} \mathrm{~N}^{r} \mathrm{~N}$ & 119.72 & & $\mathrm{NVN}^{m} \mathrm{~N}^{m} \mathrm{~N}$ & 25.80 & \\
\hline $\mathrm{N}^{r} \mathrm{~N}^{r} \mathrm{~N}^{m} \mathrm{~N}^{r} \mathrm{~N}$ & 119.72 & & $\mathrm{VVN}^{m} \mathrm{~N}^{r} \mathrm{~N}$ & 25.80 & 0.096 \\
\hline & & & $V_{V N} N^{m} N^{m}$ & 25.80 & \\
\hline $\mathrm{N}^{m} \mathrm{~N}^{r} \mathrm{~N}^{r} \mathrm{~N}^{m} \mathrm{~N}$ & 119.55 & & & & \\
\hline $\mathrm{VN}^{r} \mathrm{~N}^{r} \mathrm{~N}^{m} \mathrm{~N}$ & 119.55 & 0.014 & $\mathrm{NVN}^{m} \mathrm{NV}$ & 25.70 & 0.101 \\
\hline $\mathrm{VN}^{r} \mathrm{~N}^{r} \mathrm{NV}$ & 119.55 & & $\mathrm{VVN}^{m} \mathrm{NV}$ & 25.70 & 0.101 \\
\hline $\begin{array}{l}\mathrm{VN}^{r} \mathrm{~N}^{r} \mathrm{~N}^{r} \mathrm{~N} \\
\mathrm{~N}^{r} \mathrm{~N}^{r} \mathrm{~N}^{r} \mathrm{~N}^{m} \mathrm{~N}\end{array}$ & 119.48 & 0.049 & & & \\
\hline$N^{\prime} N^{\prime} N^{\prime} N^{m} N$ & 119.48 & & & & \\
\hline $\mathrm{N}^{r} \mathrm{~N}^{r} \mathrm{~N}^{r} \mathrm{~N}^{r} \mathrm{~N}$ & 119.41 & 0.042 & NVNVV & 24.80 & 0.103 \\
\hline
\end{tabular}

${ }^{\mathrm{a}}$, Coracemo. ${ }^{\mathrm{b} m}$, Comeso. 
Table VII. Parameter $\delta_{\min }^{\prime} \times 1000^{\mathrm{a}}$ evaluated for various statistics on poly(acrylonitrile(N)-co-vinylidene chloride(V)) sample

\begin{tabular}{|c|c|c|c|c|c|c|c|c|c|}
\hline \multirow{5}{*}{ Carbon type } & \multicolumn{9}{|c|}{$\delta_{\min }^{\prime} \times 1000$} \\
\hline & \multicolumn{8}{|c|}{ General statistical model } & \multirow{2}{*}{$\begin{array}{c}\begin{array}{c}\sigma \text {-Parameter } \\
\text { model }\end{array} \\
\text { Correlation }\end{array}$} \\
\hline & \multicolumn{4}{|c|}{ Non-correlation } & & \multicolumn{3}{|c|}{ Correlation } & \\
\hline & \multirow{2}{*}{ Cotacticity } & \multicolumn{3}{|c|}{ Monomer sequence ${ }^{b}$} & \multirow{2}{*}{ Cotacticity } & \multicolumn{3}{|c|}{ Monomer sequence } & Monomer \\
\hline & & Bernoulli & $\begin{array}{c}\text { lst } \\
\text { Markov }^{\mathrm{c}}\end{array}$ & $\begin{array}{c}\text { 2nd } \\
\text { Markov }^{d}\end{array}$ & & Bernoulli & $\begin{array}{c}\text { 1st } \\
\text { Markov }\end{array}$ & $\begin{array}{c}\text { 2nd } \\
\text { Markov }\end{array}$ & $\begin{array}{c}\text { 1st } \\
\text { Markov }\end{array}$ \\
\hline \multirow{3}{*}{$\mathrm{CN}$} & Bernoulli & 5.08 & 3.89 & 3.77 & \multirow{3}{*}{$\begin{array}{l}\text { Bernoulli } \\
\text { lst } \\
\text { Markov }\end{array}$} & 5.08 & 3.89 & - & 3.89 \\
\hline & $\begin{array}{l}\text { lst } \\
\text { Markov }\end{array}$ & 5.00 & 3.72 & 3.62 & & - & - & 5.78 & \\
\hline & $\begin{array}{l}\text { 2nd } \\
\text { Markov }\end{array}$ & 3.02 & 2.44 & ${\underline{1.90^{\mathrm{e}}}}^{\mathrm{e}}$ & & & & & \\
\hline \multirow{3}{*}{$\mathrm{CN}$} & Bernoulli & 5.24 & 5.21 & 4.99 & \multirow{3}{*}{$\begin{array}{l}\text { Bernoulli } \\
\text { 1st } \\
\text { Markov }\end{array}$} & 5.24 & 5.21 & - & 1.51 \\
\hline & $\begin{array}{l}\text { 1st } \\
\text { Markov }\end{array}$ & 5.23 & 5.21 & 4.99 & & - & - & 4.99 & \\
\hline & $\begin{array}{l}\text { 2nd } \\
\text { Markov }\end{array}$ & 5.23 & 4.99 & $\underline{4.97}$ & & & & & \\
\hline
\end{tabular}

${ }^{a} \delta_{\text {min }}^{\prime}$, minimized value of $\delta^{\prime}$ defined by eq 35 , (in these cases, $N=14$ for $\mathrm{CN}$ carbon and $N=13$ for $\mathrm{CH}$ carbon). ${ }^{b}$ Monomer sequence, monomer unit sequence. ${ }^{\mathrm{c}}$ 1st $\mathrm{M}, 1$ st order Markov statistics. ${ }^{\mathrm{d}}$ 2nd M, 2nd order Markov statistics. ${ }^{\mathrm{e}}$ Underline, the most suitable statistics for each carbon type.

Table VIII. Statistical parameters for the most suitable statistical model on poly(acrylonitrile(N)-co-vinylidene chloride(V)) sample

\begin{tabular}{ccccccccc}
\hline \multirow{2}{*}{$\begin{array}{c}\text { Carbon } \\
\text { type }\end{array}$} & \multicolumn{7}{c}{ Statistical parameter in the most suitable statistical model } \\
\cline { 2 - 8 } & $P_{(\mathrm{N} / \mathrm{NN})}$ & $P_{(\mathrm{N} / \mathrm{NV})}$ & $P_{(\mathrm{N} / \mathrm{VN})}$ & $P_{(\mathrm{N} / \mathrm{VV})}$ & $P_{(m / m m)}$ & $P_{(m / m r)}$ & $P_{(m / r m)}$ & $P_{(m / r r)}$ \\
\hline CN & 0.645 & 0.727 & 0.649 & 0.800 & 0.506 & 0.523 & 0.474 & 0.509 \\
$\mathrm{CH}$ & 0.712 & 0.842 & 0.653 & 0.757 & & Parameters cannot be fixed & \\
\hline
\end{tabular}

${ }^{\mathrm{a}}$ The most suitable statistical model is [2nd order Markov]-[2nd order Markov](non-correlation).

0.723 , respectively. These values are in vicinity to feed monomer ratio of $\mathrm{AN}$ to $\mathrm{VdCl}_{2}$ (72 to 28), showing azeotropic polymerization.

Cotacticity parameter $P_{m}$ is obtained through use of eq 19 from first order Markov parameters, obtained from analysis on the nitrile carbon peaks and agrees very well with $P_{m}=0.51-0.52$ evaluated by Yamazaki et al. ${ }^{15}$

Monomer reactivity ratio of copolymerization $^{24}$ has also been discussed. Monomer reactivity ratios of terminal model, $r_{\mathrm{N}}$ and $r_{\mathrm{V}}$, are related to the probabilities of the first order Markov statistics, $P_{(\mathrm{V} / \mathrm{N})}$ and $P_{(\mathrm{N} / \mathrm{V})}$, through the relations, ${ }^{25}$

$$
\begin{aligned}
& r_{\mathrm{N}}=\frac{1}{x}\left(\frac{1}{P_{(\mathrm{V} / \mathrm{N})}}-1\right) \\
& r_{\mathrm{V}}=x\left(\frac{1}{P_{(\mathrm{N} / \mathrm{V})}}-1\right),
\end{aligned}
$$


Table IX. Monomer reactivity ratio of copolymerization for poly(acrylonitrile(N)-co-vinylidene chloride(V)) sample

\begin{tabular}{cccccc}
\hline & $\mathrm{CH}$ & $\mathrm{CN}$ & $\mathrm{CH}_{2}$ & $\mathrm{CCl}_{2}$ & Literature \\
\hline$r_{\mathrm{N}}$ & 0.90 & - & 0.86 & - & 4 \\
& 0.882 & 0.710 & - & - & This work \\
$r_{\mathrm{V}}$ & - & - & 0.64 & 0.55 & 4 \\
& 0.538 & 0.875 & - & - & This work \\
\hline$r_{\mathrm{NN}}$ & 0.962 & 0.707 & - & - & This work \\
$r_{\mathrm{NV}}$ & 0.482 & 0.965 & - & - & This work \\
$r_{\mathrm{VN}}$ & 0.732 & 0.719 & - & - & This work \\
$r_{\mathrm{Vv}}$ & 0.825 & 0.643 & - & & This work \\
\hline
\end{tabular}

where $x$ means initial monomer concentration ratio $\left(C_{\mathrm{No}} / C_{\mathrm{vo}}\right)$. Monomer reactivity ratios of penultimate model, $r_{\mathrm{NN}}, r_{\mathrm{NV}}, r_{\mathrm{VN}}$, and $r_{\mathrm{Vv}}$, have following relations to the probabilities, $\alpha, \beta, \gamma$, and $\delta$, of the second order Markov statistics ${ }^{25}$ :

$$
\begin{aligned}
& r_{\mathrm{NN}}=\frac{1}{x} \frac{\alpha}{\bar{\alpha}} \\
& r_{\mathrm{NV}}=x \frac{\bar{\beta}}{\beta} \\
& r_{\mathrm{VN}}=\frac{1}{x} \frac{\gamma}{\bar{\gamma}} \\
& r_{\mathrm{VV}}=x \frac{\bar{\delta}}{\delta}
\end{aligned}
$$

Table IX compiles monomer reactivity ratios of terminal and penultimate models estimated using above equations. $P_{(\mathrm{N} / \mathrm{v})}$ and $P_{(\mathrm{V} / \mathrm{N})}$ were calculated using eq 22 . This table shows that monomer reactivity ratios of terminal model estimated from methine carbon region of ${ }^{13} \mathrm{C}$ NMR spectra in the present article agree fairly well with those reported by Yamazaki et al., ${ }^{4}$ but monomer reactivity ratios from the nitrile carbon have rather different values from those by Yamazaki et al. The monomer reactivity ratios of penultimate model, also distribute at higher value of range, $0.6-0.96$ except one value of $r_{\mathrm{NV}}$, although there appear some unevenness. The difference between values of $r_{\mathrm{NV}}$ obtained from methine and nitrile carbon region, 0.482 and 0.964 , respectively, is rather large, but this is due to the difference between values of $P_{(\mathrm{V} / \mathrm{NV})}$ estimated from both types of carbon, which values are 0.273 and 0.158 . This problem can be solved by such more accurate spectroscopic method as NMR in order to observe microstructure of polymer in the future.

Peaks for methine and nitrile carbon region in ${ }^{13} \mathrm{C}$ NMR spectra show complicated splitting caused by the presence of cotacticity. Especially, those of the nitrile carbon are so much complicated that they have not been analyzed by Yamazaki et al. for estimation of monomer reactivity ratios. If the systematic method proposed in the present article is employed, proper information of monomer unit sequence to the extent of penultimate level can be obtained from methine and nitrile carbon data omitting cotactic factors in case where there does or does not exist a correlation between monomer unit sequence and its cotacticity. Generally speaking, NMR chart of copolymer containing cotacticity becomes much intricate, however, it is proved concretely that the systematic method proposed in the present study is highly useful to obtain reliable information about monomer unit sequence. It is obviously that this method is effective for both correlation and non-correlation cases between monomer unit sequence and its cotacticity. 


\section{CONCLUSION}

1) In the previous article, a method had been proposed for evaluation of monomer unit sequence distribution combined with its cotacticity bi-component copolymer system, assuming that the propagation reaction is completely expressed in terms of combination of statistics, in which each of both monomer units has the possibility of yielding stereoregular homopolymer. In the present article, the original method was modified by taking account of pentad sequences for estimation of copolymer sequence distribution where only one monomer unit has chirality, i.e., a possibility of yielding stereoregular homopolymer.

2) The applicability of the method was examined by poly $\left(\mathrm{AN}-\mathrm{co}-\mathrm{VdCl}_{2}\right)$, of which full ${ }^{13} \mathrm{C}$ NMR assignments for methine and nitrile carbon peaks attributed to pentad sequences were already given by Yamazaki et al. ${ }^{15}$
3) If the systematic method presented in this study is employed, precise information of monomer unit sequence can be gained by omitting factors of cotacticity completely from highly complicated data of ${ }^{13} \mathrm{C}$ NMR for both correlation and non-correlation cases between monomer unit sequence and its cotacticity.

4) Application of the method to the poly $\left(\mathrm{AN}-\mathrm{co}-\mathrm{VdCl}_{2}\right)$ sample shows that the sequence distributions of the monomer unit and its cotacticity are not correlative to each other and both of them obey second order Markov statistics.

5) Enumeration of sorts of $n$-length copolymer sequence system, in which one monomer unit only possesses chirality, has been carried out using difference equation method.

Acknowledgment. Authors are deeply indebted to The Society of Polymer Science, Tokyo, Japan, for the permission to copy Table VI.

\section{APPENDIX}

\section{A. Enumeration of Sorts of $n$-Length Copolymer Sequence in Which One Monomer Unit Only} Has Chirality

(1) Partial Diad-Monad Directive Sequence. If the coefficient matrix in eq 1 is written as A, the difference equation can be solved as below,

$$
\left[\begin{array}{c}
{ }_{\mathrm{a}} N_{\mathrm{a}}(n) \\
{ }_{\mathrm{a}} N_{\mathrm{b}}(n) \\
{ }_{\mathrm{b}} N_{\mathrm{a}}(n) \\
{ }_{\mathrm{b}} N_{\mathrm{b}}(n)
\end{array}\right]=\mathbf{A}\left[\begin{array}{c}
{ }_{\mathrm{a}} N_{\mathrm{a}}(n-2) \\
{ }_{\mathrm{a}} N_{\mathrm{b}}(n-2) \\
{ }_{\mathrm{b}} N_{\mathrm{a}}(n-2) \\
{ }_{\mathrm{b}} N_{\mathrm{b}}(n-2)
\end{array}\right]=\mathbf{A}^{[n / 2]}\left[\begin{array}{c}
{ }_{\mathrm{a}} N_{\mathrm{a}}\left(\eta_{n}\right) \\
{ }_{\mathrm{a}} N_{\mathrm{b}}\left(\eta_{n}\right) \\
{ }_{\mathrm{b}} N_{\mathrm{a}}\left(\eta_{n}\right) \\
{ }_{\mathrm{b}} N_{\mathrm{b}}\left(\eta_{n}\right)
\end{array}\right]
$$

where maximum value less than $x$ is referred to as $[x]$, and $\eta_{n}$ is a parameter having value 1 or 2 if $n$ is even or odd, respectively.

If $\mathbf{A}^{[n / 2]}$ is written as $\mathbf{Q}$, it can be calculated by following procedure using the diagonalization matrix of $\mathbf{A}$, as defined by $\mathbf{T}$, and its inverse matrix $\mathbf{T}^{-1}$ :

$$
\mathbf{Q}=\mathbf{T}^{-1}\left(\mathbf{T A T}^{-1}\right)^{[n / 2]} \mathbf{T}
$$

because

$$
\left(\mathbf{T A T}^{-1}\right)^{[n / 2]}=\mathbf{T A}^{[n / 2]} \mathbf{T}^{-1}=\mathbf{T Q T}^{-1}
$$

Since the three eigenvalues of matrix $\mathbf{A}$ are 1 as double roots and $(7 \pm 3 \sqrt{5}) / 2,(7+3 \sqrt{5}) / 2$, and $(7-3 \sqrt{5}) / 2$ will be written by $\omega_{1}$ and $\omega_{2}$, respectively. The diagonalization matrix $\mathbf{T}$, and 
its inverse matrix $\mathbf{T}^{-1}$ are given by,

$$
\begin{aligned}
& \mathbf{T}=\left[\begin{array}{cccc}
1 & 0 & -1 & -1 \\
-1 & 1 & 0 & 1 \\
\frac{9+3 \sqrt{5}}{2} & \frac{3+3 \sqrt{5}}{2} & \frac{3+3 \sqrt{5}}{2} & 3 \\
\frac{9-3 \sqrt{5}}{2} & \frac{3-3 \sqrt{5}}{2} & \frac{3-3 \sqrt{5}}{2} & 3
\end{array}\right] \\
& \mathbf{T}^{-1}=\left[\begin{array}{cccc}
\frac{1}{5} & -\frac{1}{5} & \frac{1}{15} & 1 \\
\frac{2}{5} & \frac{3}{5} & \frac{-1+\sqrt{5}}{30} & -\frac{1+\sqrt{5}}{30} \\
\frac{3}{5} & -\frac{2}{5} & \frac{-1+\sqrt{5}}{30} & -\frac{1+\sqrt{5}}{30} \\
-\frac{1}{5} & \frac{1}{5} & \frac{3-\sqrt{5}}{30} & \frac{3+\sqrt{5}}{30}
\end{array}\right]
\end{aligned}
$$

and then $\mathbf{Q}$ is derived as

$$
\begin{aligned}
& \mathbf{Q}=\left[\begin{array}{cc}
\frac{2}{5}+\frac{3+\sqrt{5}}{10} \omega+\frac{3-\sqrt{5}}{10} \omega^{\prime} & -\frac{1}{5}+\frac{1+\sqrt{5}}{10} \omega+\frac{1-\sqrt{5}}{10} \omega^{\prime} \\
-\frac{1}{5}+\frac{1+\sqrt{5}}{10} \omega+\frac{1-\sqrt{5}}{10} \omega^{\prime} & \frac{2+\omega+\omega^{\prime}}{5} \\
-\frac{1}{5}+\frac{1+\sqrt{5}}{10} \omega+\frac{1-\sqrt{5}}{10} \omega^{\prime} & \frac{-3+\omega+\omega^{\prime}}{5} \\
\frac{2+\omega+\omega^{\prime}}{5} & \frac{1}{5}+\frac{-1+\sqrt{5} \omega+\frac{-1-\sqrt{5}}{10} \omega^{\prime}}{10}
\end{array}\right. \\
& -\frac{1}{5}+\frac{1+\sqrt{5}}{10} \omega+\frac{1-\sqrt{5}}{10} \omega^{\prime} \quad \frac{-2+\omega+\omega^{\prime}}{5} \\
& \frac{3+\omega+\omega^{\prime}}{5} \quad \frac{1}{5}+\frac{-1+\sqrt{5}}{10} \omega+\frac{-1-\sqrt{5}}{10} \omega^{\prime} \\
& \frac{2+\omega+\omega^{\prime}}{5} \quad \frac{1}{5}+\frac{-1+\sqrt{5}}{10} \omega+\frac{-1-\sqrt{5}}{10} \omega^{\prime} \\
& \left.\frac{1}{5}+\frac{-1+\sqrt{5}}{10} \omega+\frac{-1-\sqrt{5}}{10} \omega^{\prime} \quad \frac{2}{5}+\frac{3+\sqrt{5}}{10} \omega+\frac{3-\sqrt{5}}{10} \omega^{\prime}\right]
\end{aligned}
$$

with

$$
\omega=\omega_{1}^{[(n-1) / 2]}
$$




$$
\omega^{\prime}=\omega_{2}^{[(n-1) / 2]}
$$

By calculating eq A.1, we obtain ${ }_{\mathrm{a}} N_{\mathrm{a}}(n),{ }_{\mathrm{a}} N_{\mathrm{b}}(n),{ }_{\mathrm{b}} N_{\mathrm{a}}(n)$, and ${ }_{\mathrm{b}} N_{\mathrm{b}}(n)$ for any $n$.

(2) Partial Diad-Monad Non-Directive Sequence. The eigenpolynomial of A defined as coefficient matrix in eq 2 is $\left(x^{2}-3 x+1\right)\left(x^{3}-8 x^{2}+9 x-3\right)$. Two and three roots of $x^{2}-3 x+1=0$ and $x^{3}-8 x^{2}+9 x-3=0$ are referred to as $p_{1}, p_{2}$ and $q_{1}, q_{2}, q_{3}$, respectively. These five roots become the eigenvalues of matrix $\mathbf{A}$. Therefore the diagonalization matrix $\mathbf{T}$ is,

$$
\mathbf{T}=\left[\begin{array}{ccccc}
-7 p_{1}+2 & -7 p_{2}+2 & 0 & 0 & 0 \\
-5 p_{1}+3 & -5 p_{2}+3 & 0 & 0 & 0 \\
4 p_{1}-1 & 4 p_{2}-1 & q_{1}-1 & q_{2}-1 & q_{3}-1 \\
-1 & -1 & q_{1} & q_{2} & q_{3} \\
2 p_{1} & 2 p_{2} & q_{1}{ }^{2}-7 q_{1}+4 & q_{2}{ }^{2}-7 q_{2}+4 q_{3}{ }^{2}-7 q_{3}+4
\end{array}\right]
$$

If parameters $p_{i j}, q_{i j}$, and $f_{i j}$ are defined as $p_{i j}=p_{i}-p_{j}, q_{i j}=q_{i}-q_{j}$, and $f_{i j}\left(a_{1}, a_{2}, a_{3}\right)=a_{1} q_{i}+a_{2} q_{i j}+$ $a_{1} q_{j}+a_{3}$, the inverse matrix $\mathbf{T}^{-1}$ is derived from eq A.7 in the form,

$$
\mathbf{T}^{-1}=\left[\begin{array}{ccccc}
\frac{-5 p_{2}+3}{11 p_{21}} & \frac{7 p_{2}-2}{11 p_{21}} & 0 & 0 & 0 \\
\frac{5 p_{1}-3}{11 p_{21}} & \frac{-7 p_{2}+2}{11 p_{21}} & 0 & 0 & 0 \\
\frac{f_{23}(5,-12,19)}{11 q_{12} q_{31}} & \frac{f_{23}(7,-6,-22)}{11 q_{12} q_{31}} & \frac{4-q_{2} q_{3}}{q_{12} q_{31}} & \frac{f_{23}(-1,1,3)}{q_{12} q_{31}} & \frac{1}{q_{12} q_{31}} \\
\frac{f_{31}(5,-12,19)}{11 q_{23} q_{12}} & \frac{f_{31}(7,-6,-22)}{11 q_{23} q_{12}} & \frac{4-q_{3} q_{1}}{q_{23} q_{12}} & \frac{f_{31}(-1,1,3)}{q_{23} q_{12}} & \frac{1}{q_{23} q_{12}} \\
\frac{f_{12}(5,-12,19)}{11 q_{31} q_{23}} & \frac{f_{12}(7,-6,-22)}{11 q_{31} q_{23}} & \frac{4-q_{1} q_{2}}{q_{31} q_{23}} & \frac{f_{12}(-1,1,3)}{q_{31} q_{23}} & \frac{1}{q_{31} q_{23}}
\end{array}\right]
$$

B. Molar Fractions of Pentad Sequences with $\left(\mathrm{A}^{m} \mathrm{~A}^{m} \mathrm{~A}^{r} \mathrm{~A}^{r} \mathrm{~A}\right)=$

\section{A Unit Centered}

(2.2) [Bernoulli]-[1st Markov] (Correlation) Model.

$$
\begin{aligned}
& \left(\mathrm{A}^{m} \mathrm{~A}^{m} \mathrm{~A}^{m} \mathrm{~A}^{m} \mathrm{~A}\right)=P_{(m \mathrm{~A} / m)}{ }^{3} X_{m} / \mathrm{D}^{\mathrm{M}(2)^{*} m r(1)} \\
& \left(\mathrm{A}^{m} \mathrm{~A}^{m} \mathrm{~A}^{m} \mathrm{~A}^{r} \mathrm{~A}\right)= \\
& P_{(m \mathrm{~A} / m)}{ }^{2}\left(P_{(r \mathrm{~A} / m)} X_{m}+P_{(m \mathrm{~A} / r)} X_{r}\right) \\
& / \mathrm{D}^{\mathrm{M}(2)^{*} m r(1)} \\
& \left(\mathrm{A}^{r} \mathrm{~A}^{m} \mathrm{~A}^{m} \mathrm{~A}^{r} \mathrm{~A}\right)= \\
& P_{(r \mathrm{~A} / m)} P_{(m \mathrm{~A} / m)} P_{(m \mathrm{~A} / r)} X_{r} / \mathrm{D}^{\mathrm{M}(2)^{*} m r(1)} \\
& \left(\mathrm{A}^{m} \mathrm{~A}^{m} \mathrm{~A}^{r} \mathrm{~A}^{m} \mathrm{~A}\right)= \\
& 2 P_{(m \mathrm{~A} / m)} P_{(m \mathrm{~A} / r)} P_{(r \mathrm{~A} / m)} X_{m} / \mathrm{D}^{\mathrm{M}(2)^{*} m r(1)}
\end{aligned}
$$$$
P_{(m \mathrm{~A} / m)} P_{(r \mathrm{~A} / r)}\left(P_{(r \mathrm{~A} / m)} X_{m}+P_{(m \mathrm{~A} / r)} X_{r}\right)
$$$$
/ \mathrm{D}^{\mathrm{M}(2)^{*} \operatorname{mr}(1)}
$$

$\left(\mathrm{A}^{r} \mathrm{~A}^{m} \mathrm{~A}^{r} \mathrm{~A}^{m} \mathrm{~A}\right)=$

$$
P_{(r \mathrm{~A} / m)} P_{(m \mathrm{~A} / r)}\left(P_{(r \mathrm{~A} / m)} X_{m}+P_{(m \mathrm{~A} / r)} X_{r}\right)
$$$$
/ \mathrm{D}^{\mathrm{M}(2)^{*} m r(1)}
$$

$\left(\mathrm{A}^{r} \mathrm{~A}^{m} \mathrm{~A}^{r} \mathrm{~A}^{r} \mathrm{~A}\right)=$

$$
2 P_{(r \mathrm{~A} / m)} P_{(r \mathrm{~A} / r)} P_{(m \mathrm{~A} / r)} X_{r} / \mathrm{D}^{\mathrm{M}(2)^{*} m r(1)}
$$

$$
\begin{aligned}
& \left(\mathrm{A}^{m} \mathrm{~A}^{r} \mathrm{~A}^{r} \mathrm{~A}^{m} \mathrm{~A}\right)= \\
& \quad P_{(r \mathrm{~A} / r)} P_{(m \mathrm{~A} / r)} P_{(r \mathrm{~A} / m)} X_{m} / \mathrm{D}^{\mathrm{M}(2)^{*} m r(1)}
\end{aligned}
$$

$$
\begin{aligned}
& \left(\mathrm{A}^{m} \mathrm{~A}^{r} \mathrm{~A}^{r} \mathrm{~A}^{r} \mathrm{~A}\right)= \\
& \quad P_{(r \mathrm{~A} / r)}{ }^{2}\left(P_{(r \mathrm{~A} / m)} X_{m}+P_{(m \mathrm{~A} / r)} X_{r}\right) / \mathrm{D}^{\mathrm{M}(2)^{*} m r(1)}
\end{aligned}
$$




$$
\begin{aligned}
& (\mathrm{BBABB})= \\
& P_{(\mathrm{B} / \mathrm{AB})}{ }^{2} P_{(\mathrm{B} / \mathrm{BA})} Y_{m r} / \mathrm{D}^{\mathrm{M}(2)^{*} m r(1)} .
\end{aligned}
$$

(3) $\sigma$-Parameter Model (Examples Only).

$$
\begin{aligned}
& \left(\mathrm{A}^{r} \mathrm{~A}^{m} \mathrm{~A}^{m} \mathrm{AB}\right)= \\
& 2 P_{\mathrm{A}} P_{(\mathrm{A} / \mathrm{A})}^{3}\left(1-P_{(\mathrm{A} / \mathrm{A})}\right) \sigma_{\mathrm{AA}}{ }^{2}\left(1-\sigma_{\mathrm{AA}}\right) \\
& \left(\mathrm{ABA}^{m} \mathrm{~A}^{r} \mathrm{~A}\right)= \\
& 2 P_{\mathrm{A}} P_{(\mathrm{A} / \mathrm{A})}{ }^{2}\left(1-P_{(\mathrm{A} / \mathrm{A})}\right)\left(1-P_{(\mathrm{B} / \mathrm{B})}\right) \\
& \times \sigma_{\mathrm{AA}}\left(1-\sigma_{\mathrm{AA}}\right) \\
& \left(\mathrm{A}^{m} \mathrm{~A}^{r} \mathrm{ABB}\right)= \\
& 2 P_{\mathrm{A}} P_{(\mathrm{A} / \mathrm{A})}{ }^{2}\left(1-P_{(\mathrm{A} / \mathrm{A})}\right) P_{(\mathrm{B} / \mathrm{B})} \sigma_{\mathrm{AA}}\left(1-\sigma_{\mathrm{AA}}\right)
\end{aligned}
$$

$\left(\mathrm{BA}^{m} \mathrm{~A}^{r} \mathrm{AB}\right)=$

$$
2 P_{\mathrm{A}} P_{(\mathrm{A} / \mathrm{A})}{ }^{2}\left(1-P_{(\mathrm{A} / \mathrm{A})}\right)^{2} \sigma_{\mathrm{AA}}\left(1-\sigma_{\mathrm{AA}}\right)
$$

$\left(\mathrm{BBA}^{r} \mathrm{AB}\right)=$

$$
2 P_{\mathrm{A}} P_{(\mathrm{A} / \mathrm{A})}\left(1-P_{(\mathrm{A} / \mathrm{A})}\right)^{2} P_{(\mathrm{B} / \mathrm{B})}\left(1-\sigma_{\mathrm{AA}}\right)
$$

\section{REFERENCES}

1. H. L. Frisch, C. Schuerch, and M. Szwarc, J. Polym. Sci., 11, 559 (1953).

2. B. D. Coleman, J. Polym. Sci., 31, 155 (1958).

3. R. L. Miller and L. E. Nielsen, J. Polym. Sci., 46, 303 (1960)

4. J. W. L. Fordham, J. Polym. Sci., 39, 321 (1959).

5. F. Price, J. Chem. Phys., 36, 209 (1962).

6. A. Miyake and R. Chujo, J. Polym. Sci., 46, 163 (1960).

7. H. L. Frisch, C. L. Mallows, and F. A. Bovey, $J$.
Chem. Phys., 45, 1565 (1966).

8. H. L. Frisch, C. L. Mallows, F. Heatley, and F. A. Bovey, Macromolecules, 6, 533 (1968).

9. F. A. Bovey, J. Polym. Sci., 62, 197 (1962).

10. E. Klesper and W. Gronski, J. Polym. Sci., Polym. Lett. Ed., 6, 661 (1969).

11. A. R. Katritzky, A. Smith, and D. E. Weiss, J. Chem. Soc. Perkin II, 1547 (1974).

12. R. Roussel and J. C. Galin, J. Macromol. Sci.-Chem., A11, 347 (1977).

13. G. S. Kapur and A. S. Brar, Polymer, 32, 1112 (1991).

14. G. S. Kapur and A. S. Brar, J. Polym. Sci., A29, 479 (1991).

15. H. Yamazaki, K. Okajima, and K. Kamide, Polym. J., 20, 1143 (1988).

16. K. Kamide and K. Hisatani, Polym. J., 24, 1377 (1992).

17. E. Klesper and G. Sielaff in "Polymer Spectroscopy," D. O. Hummel, Ed., Verlag Chemie, Weinheim/ Bergstr., 1974, p 209.

18. E. Klesper and G. Sielaff in "Polymer Spectroscopy," D. O. Hummel, Ed., Verlag Chemie, Weinheim/ Bergstr., 1974, p 272.

19. K. Kamide, H. Yamazaki, K. Okajima, and K. Hikichi, Polym. J., 17, 1291 (1985).

20. K. Ito, S. Kondo, Y. Yamashita, and H. Ishii, Kogyo Kagaku Zasshi, 73, 600 (1970).

21. D. B. Bailey and P. M. Henrichs, J. Polym. Sci., 16, 3185 (1978).

22. J. König and D. Wendish, Angew. Makromol. Chem., 98, 255 (1981).

23. E. Klesper and G. Sielaff in "Polymer Spectroscopy," D. O. Hummel, Ed., Verlag Chemie, Weinheim/ Bergstr., 1974, p 205.

24. F. R. Mayo and F. M. Lewis, J. Am. Chem. Soc., 66, 1594 (1944).

25. K. Ito and Y. Yamashita, J. Polym. Sci., A3, 2165 (1965). 